\title{
THE INTERNATIONAL EVOLUTION OF MEDIATION: A CALL FOR DiALOGUE AND DELIBERATION
}

\author{
Thomas J Stipanowich*
}

\begin{abstract}
The following article is a revised and expanded version of lectures delivered by the author at the Victoria University of Wellington School of Law and the Faculty of Law, University of Auckland in October, 2014 as the New Zealand Law Foundation's International Dispute Resolution Visiting Scholar. The author posits that the mounting global preoccupation with mediation, resulting in a proliferating array of institutions, programmes, laws and regulations; an international "evangelical" movement; and growing impetus for an international convention promoting the recognition and enforcement of mediated settlement agreements, should be accompanied by our collective reflection, dialogue and discernment regarding where we have come to and where we are going. He urges active discussion and deliberation on a host of questions and concerns, including (1) our fundamental understanding of the nature and practice of mediation; (2) the impact of lawyers on mediation, and the appropriate interplay between client and counsel in making process choices; (3) the influence of culture and of legal traditions; (4) the interplay between the facilitation of settlement and processes of adjudication; (5) the potential impact of mediation on the rendition of
\end{abstract}

* William H Webster Chair in Dispute Resolution, Professor of Law, Pepperdine University School of Law; Academic Director, Straus Institute for Dispute Resolution. Professor Stipanowich thanks the New Zealand Law Foundation; Dr Petra Butler, Associate Professor, Victoria University of Wellington School of Law; Deborah Hart, Executive Director of the Arbitrators' and Mediators' Institute of New Zealand Inc (AMINZ); and Dr Caroline E Foster, Associate Professor and Director of Doctoral Studies, Faculty of Law, University of Auckland, for facilitating and hosting his visit and series of lectures. Thanks also go to those who shared helpful insights, including Jay Folberg; Wolf von Kumberg; Dr Fan Kun; Jeremy Lack; Gu Xuan, Candidate for the LLM in Dispute Resolution with a Concentration in International Commercial Arbitration; Ying Wang, LLM, Straus Institute/Pepperdine University School of Law (2015); and participants in the Workshop "Reimagining Corporate Conflict Management", September 2014, co-sponsored by the Straus Institute, Pepperdine School of Law and the Graziadio School of Business and Management, Pepperdine University. The author appreciates the research assistance provided by Karinya Verghese, LLM in Dispute Resolution (2014); Marcio Vasconcellos, Esq, Candidate for the LLM in Dispute Resolution with a Concentration in International Commercial Arbitration; and Doua Alattas, Candidate for the JD and LLM in Dispute Resolution at Pepperdine University School of Law, as well as Matthew O'Brien, Pepperdine School of Law Class of 2015. 
justice. This conversation should be augmented by an assessment of current mega-trends - the challenges and opportunities presented by information technology, neuropsychology, the mining of big data, and initiatives aimed at institutionalising or professionalising mediation. Finally, there should be a new examination of heretofore-unfulfilled opportunities, such as the "upstream" (that is, early and pre-litigation) use of skills and insights gleaned from our experience with mediation for the purpose of sustaining and improving relationships.

\section{INTRODUCTION: REVERBERATIONS OF THE QUIET REVOLUTION}

At a time when unprecedented attention is being paid to the resolution of conflict, and many are expressing concerns about rising costs, lengthening cycle time, and other aspects of international litigation and arbitration, ${ }^{1}$ there is intensified focus on mediation and other approaches aimed at actively managing and resolving conflict efficiently, informally and consensually. ${ }^{2}$ Its proponents tout mediation as an informal and flexible path to cost and time-saving, as well as overcoming cultural barriers, improving communications, restoring or maintaining relationships, promoting confidentiality and producing more creative, satisfactory and durable resolutions. ${ }^{3}$ In less than four decades, the North American model of "modern" mediation has seeded a wide variety of public and private initiatives worldwide, given impetus to calls for the use of mediation in the resolution of international commercial and investment disputes, ${ }^{4}$ and even inspired a push for a new kind of international convention. ${ }^{5}$ But our broadening international conversation should be accompanied by

1 Daniel E Gonzalez, Maria Catalina Carmona and Roland Potts "Controlling the rising costs of arbitration" Financier Worldwide (online ed, Birmingham (England), October 2014); and Thomas J Stipanowich "Reflections on the State and Future of Commercial Arbitration: Challenges, Opportunities, Proposals" (2014) 25 Am Rev Int'l Arb 297 at 341-343.

2 Thomas J Stipanowich "Arbitration: The 'New Litigation"' [2010] U Ill L Rev 1 at 24-32. The flexible nature of mediation has led to it possessing multiple, yet similar, definitions. See for example "Mediation" US Equal Employment Opportunity Commission <www.eeoc.gov> ("Mediation is an informal and confidential way for people to resolve disputes with the help of a neutral mediator who is trained to help people discuss their differences. The mediator does not decide who is right or wrong or issue a decision. Instead, the mediator helps the parties work out their own solutions to problems."); American Bar Association: Section of Dispute Resolution Preparing for Mediation at 2 ("Mediation is a process in which an impartial third party (the mediator) facilitates communication and negotiation and promotes voluntary decision making by the parties to the dispute. Mediators help parties understand each other's perspectives and discuss options for settlement. Mediators do not decide who is right or who is wrong. Whether parties choose mediation or a court orders them to try mediation, the decision whether to settle is always up to the parties. The mediator has no authority to impose a settlement on the parties.").

3 See "How Courts Work: Mediation" American Bar Association: Division for Public Education <www.american bar.org>; and Stipanowich, above n 2.

4 "Mediation of Investor-State Conflicts" (2014) 127 Harv L Rev 2543.

5 See "How Users View the Proposal for a UN Convention on the Enforcement of Mediated Settlements" (2015) International Mediation Institute <www.imimediation.org>. 
more active mutual engagement and discernment. There are questions and concerns that should be addressed if the varied approaches that fall under the rubric of "mediation" are to attain their maximum global effectiveness as a pathway to the resolution of disputes and the management of conflict within relationships.

Although forms of mediation have been in play for thousands of years, ${ }^{6}$ our present, evolving global preoccupation with mediation and other techniques for managing conflict was prefigured by developments in the United States beginning nearly four decades ago. ${ }^{7}$ That "Quiet Revolution" sprang from multiple wellsprings, including concerns about the perceived risks and costs of litigation as well as delays resulting from crowded court dockets, ${ }^{8}$ and the desire to empower parties to more effectively achieve a resolution of their own disputes and even sustain, restore or transform human relationships. ${ }^{9}$ This growing wave of change produced hundreds of court-connected programmes aimed at promoting negotiated or mediated settlement of litigated cases; analogous measures sponsored by numerous federal and state agencies; myriad neighbourhood justice centres or community-based mediation programmes; and a host of bodies or groups (from bar associations and non-governmental organisations (NGOs), to for-profit entities) aimed at promoting or providing education, training or professional dispute resolution services. Some of the organisations with which I have been affiliated, including the Center for Public Resources (CPR) (later renamed the CPR Institute for Dispute Resolution, and more recently, the International Institute for Conflict

6 See below Part II: C: The Impact of Culture and Legal Systems at 1213. In the United States, mediation was well-established as a method for the resolution of labour disputes even before the present era. See "A Timeline of Events in Modern American Labor Relations" Federal Mediation \& Conciliation Service <www.fmcs.gov> (tracing the first government mediated labour settlement back to President Van Buren's mediation with striking shipyard workers in 1838).

7 See generally Linda R Singer "The Quiet Revolution in Dispute Settlement" (1989) 7 Mediation Quarterly 105. See also Penny Brooker Mediation Law: Journey through Institutionalism to Juridification (Routledge, London, 2013) at 13 ("The Modern Mediation Movement in the USA is said to have increased apace from the 1970s, and then transferred to England and Australia in the 1980s and to European civil countries and South Africa in the 1990s.).

8 See Singer, above $\mathrm{n} 7$.

9 See Robert A Baruch Bush and Joseph P Folger The Promise of Mediation: The Transformative Approach to Conflict (revised ed, Jossey Bass, San Francisco, 2005) at 22-23 ("When both [empowerment and recognition] are held central in the practice of mediation, parties are helped to transform their conflict interaction - from destructive to constructive - and to experience the personal effects of such transformation."). Some proponents of change envisioned the potential for a systemic shift from the "advocate-controlled, adversarial, formalized, rights-based, lengthy and costly" to "client-controlled, cooperative, relational, informal, interest-based, flexible, early, expeditious and efficient": Thomas J Stipanowich "Managing Construction Conflict: Unfinished Revolution, Continuing Evolution" (2014) 34 Constr Lwyr 13 at 13. 
Prevention \& Resolution $)^{10}$ and Pepperdine's Straus Institute for Dispute Resolution, ${ }^{11}$ were early and abiding - manifestations of the Quiet Revolution.

While by no means the only locus of change, mediation was the epicentre of the Quiet Revolution and the mainstay of court-connected and other ADR programmes. ${ }^{12}$ Mediation is increasingly featured in contractual stepped procedures for resolving disputes, ${ }^{13}$ and in many parts of the United States, it is almost unimaginable that a case would proceed through litigation without at least one "stop" along the way for mediation. ${ }^{14}$ One strong indicator of the pre-eminence of mediation in the landscape of dispute resolution was the response of hundreds of corporate counsel at Fortune 1,000 companies to a 2011 canvas following up on a similar study in $1997 .{ }^{15}$ According to data from the survey, which appears to have been reflective of the practices and perspectives of

10 CPR was founded in 1979. The author was President and CEO of the organisation from 2001 to 2006. Among CPR's many efforts to promote and gather information regarding the use of mediation were an early Survey on European Business Mediation (a canvas of corporate counsel in EU countries) and the first annual European Business Mediation Congress, convened in The Hague in October 2004. The Congress attracted 140 attendees, including representatives from many leading law firms and corporations. CPR also published one of the first books on commercial mediation in Europe. See generally Nancy Nelson and others Commercial Mediation in the EU (CPR Institute Master Guide Series, New York, 2005).

11 The Straus Institute was founded in 1986. The author joined the Pepperdine Faculty and became co-director (Academic Director) of the Institute in 2006.

12 "Beginning in the mid-1980s, with the widespread adoption of alternative dispute resolution programs in federal and state courts, mediation became an integral component of [the] system of 'litigotiation'": Randall Kiser How Leading Lawyers Think: Expert Insights Into Judgment and Advocacy (Springer, 2011) at 203 (interior quotation marks added). For a discussion of the term "ADR", see Singer, above n 7; and Thomas J Stipanowich and J Ryan Lamare "Living with ADR: Evolving Perceptions and Use of Mediation, Arbitration, and Conflict Management in Fortune 1,000 Corporations" (2014) 19 Harv Negot L Rev 1 at $2-$ 7.

13 Stipanowich, above n 2, at 29-30.

14 Mediation comes into play in civil actions ranging from small claims to class and mass tort actions, and at the appellate level. See for example Heather Scheiwe Kulp "Increasing Referrals to Small Claims Mediation Programs: Models to Improve Access to Justice" (2013) 14 Cardozo J Conflict Resol 361; American Arbitration Association Mass Claims ADR Programs and Federal ADR Programs (describing the ADR processes applied by the American Arbitration Association or the federal Government in recent years to mass claims disputes); and Robert J Niemic Mediation \& Conference Programs in the Federal Courts of Appeals: a sourcebook for judges and lawyers (2nd ed, Federal Judicial Center, Washington DC, 2006) (discussing the growth of appellate mediation programmes at the federal level). Mediation is also widely employed in some settings involving criminal conduct, including for the purpose of facilitating victim/offender reconciliation. American Bar Association: Section of Dispute Resolution Mediation in Criminal Matters: Survey of ADR and Restorative Justice Programs (survey of available ADR resources for criminal justice organised by state).

15 See Stipanowich and Lamare, above n 12, at 7-18. It is likely that the respondents, many of whom were located in the United States, were heavily influenced by United States developments. 
United States counsel, mediation was employed by nearly all companies, ${ }^{16}$ and was brought to bear more frequently on a wide array of business-related disputes. ${ }^{17}$ A large majority of respondents viewed its continued usage by their companies as "likely" or "very likely". ${ }^{18}$

The Quiet Revolution gradually produced large and growing cadres of self-described dispute resolution professionals who devote some or all of their time to mediating cases. ${ }^{19}$ Introductory training programmes have attracted thousands of participants over the last three decades, and demand remains unabated. Mediation is also a key component of a growing number of academic dispute resolution programmes; Straus' academic curriculum consists of more than three dozen different courses, with programmes leading to an LLM, Masters in Dispute Resolution or a Certificate in Dispute Resolution.

The growth of a professional class of mediators spurred the development of, and was in turn spurred by, national associations such as the American College of Civil Trial Mediators, the Academy of Professional Family Mediators and the National Association for Community Mediation. Another of the leading organisations of individuals with established reputations and extensive experience as professional mediators is the International Academy of Mediators (IAM), an organisation founded in 1996 by mediators who focused primarily on the resolution of civil cases, a kind of mainstream mediation practice. ${ }^{20}$ A 2014 survey co-sponsored by the IAM and the Straus Institute for Dispute Resolution at Pepperdine University (Straus Institute) ${ }^{21}$ revealed a group

16 About 97 per cent of responding corporate counsel said their company used mediation during the prior three years: Stipanowich and Lamare, above n 12, at 41, chart F.

17 At 45 , chart G.

18 At 50, table N. The data regarding mediation contrasted with perceptions regarding future use of arbitration. See at 51 , table $\mathrm{O}$.

19 This transition to mediation practice is sometimes depicted in terms of a virtual land rush by retiring advocates and judges. See for example Kiser, above n 12, at 217: "Everybody's a mediator now. You're retired or else your practice went to hell in a hand basket."

20 IAM was formed in 1996 by a group of professional mediators from the United States and Canada. The founders were from California, Pennsylvania, Michigan, Ontario, Texas and Illinois. The membership initially consisted primarily of United States and Canadian mediators, but quickly expanded to include mediators from the United Kingdom and other countries. Although IAM members' caseloads tend to be diverse, the organisation does not include mediators who focus primarily on divorce and domestic (family) disputes.

21 See generally International Academy of Mediators and Straus Institute Survey on Mediator Practices and Perceptions (2014) [referred to as the "IAM/Straus Institute Survey" or the "Survey"] (Survey and data on file with the author). The Survey was distributed online to 153 respondents, all IAM fellows. Eighty-five per cent, or 130 individuals, participated in the Survey. The respondent pool included individuals who stated they "regularly practised" in Africa; Asia, including the Middle East; Australia and New Zealand; Canada; Europe (both Western and Eastern, with a majority from the United Kingdom); Latin America; and the 
comprised predominantly of mediators practising in the United States, ${ }^{22}$ all of whom began mediating since 1980; nearly half did not mediate until the mid-1990s. ${ }^{23}$ If one could describe a "typical" respondent to the Survey, it would be a male in his early 60 s who had mediated for 20 to 25 years, who is employed full-time and devotes the vast majority of his working hours to mediation, and who has mediated more than 1,000 disputes. He handles a diverse caseload of more than 50 cases a year.

Outside the boundaries of the United States, the "modern" American evolution of mediation was first emulated to some degree in other common law countries - notably, the United Kingdom and Commonwealth entities Canada, Australia and New Zealand. ${ }^{24}$ Mediation practice has been evolving in the United Kingdom for more than three decades, ${ }^{25}$ thanks in part to private organisations that took the lead in developing a professional infrastructure for mediation in the United Kingdom. ${ }^{26}$ The most influential of these organisations is the Centre for Effective Dispute Resolution (CEDR), founded in 1990. ${ }^{27}$ According to a 2012 Mediation Audit, about 8,000 commercial and civil cases are now mediated each year in England and Wales. ${ }^{28}$ In Canada, similarly, "mediation has evolved into a leading component of conflict resolution". ${ }^{29}$

Mediation is also well established and well integrated into the legal system in New Zealand. Although the country has no general mediation statute, provisions for mediation may be found in

United States. These and other data from the IAM/Straus Institute Survey will be published in Thomas J Stipanowich and Zachary P Ulrich "The Diverse Practices and Perspectives of Experienced Mediators: Insights from an International Survey" (forthcoming).

22 Ninety-four of 128 respondents, or about 73.4 per cent of the group, practised in the United States.

23 The author's first experience with mediation was in 1981, as an advocate in what was probably one of the first uses of mediation in a complex construction case in the United States. He did not act as a mediator, however, until nearly a decade later.

24 Brooker, above $\mathrm{n} 7$, at 13.

25 Andrew Hildebrand "The United Kingdom" in Giuseppe De Palo and Mary B Trevor (eds) EU Mediation: Law and Practice (Oxford University Press, Oxford, 2012) 374.

26 Jens M Scherpe and Bevan Marten "Mediation in England and Wales: Regulation and Practice" in Klaus J Hopt and Felix Steffek (eds) Mediation: Principles And Regulation In Comparative Perspective (Oxford University Press, Oxford, 2013) 365.

27 Centre for Effective Dispute Resolution "About" <www.cedr.com>.

28 Hildebrand, above n 25 , at 390

29 Clifford M Hendler and Alicia K Kuin "Canada, Ontario" in Manon Schonewille and Fred Schonewille (eds) The Variegated Landscape of Mediation: A Comparative Study of Mediation Regulation and Practices in Europe and the World (Eleven International Publishing, The Hague, 2013) 568 at 576. 
more than 60 statutes. ${ }^{30}$ The maturity of mediation practice in New Zealand is reflected through the establishment of the Arbitrators' and Mediators' Institute of New Zealand (AMINZ), "the leading body in New Zealand for people working in the area of dispute resolution". ${ }^{31}$ A "not-for-profit organisation dedicated to upholding, certifying and promoting the highest standards in mediation and arbitration, and other forms of dispute resolution," AMINZ functions as a networking and convening body as well as a trainer and coordinator of educational programmes.

The reverberations of the Quiet Revolution have been felt throughout the world, as reflected in the development of international and national standards and the creation of institutions providing mediation services. Among the most prominent responses was a European Union Directive designed to promote the establishment of a formal framework for cross-border civil and commercial mediation. ${ }^{32}$ In drafting the Directive, the European Commission and Parliament were guided by the principles of predictability and flexibility, producing a framework which left much to the interpretation and initiative of individual European states. ${ }^{33}$

In 2002, the United Nations Commission on International Trade Law (UNCITRAL) adopted a Model Law on International Commercial Conciliation, a document intended to facilitate the development of harmonious legal frameworks for "proceedings in which a person or a panel of persons assists the parties in their attempt to reach an amicable settlement of their dispute". ${ }^{34}$

30 Heyo Berg "Mediation in New Zealand: Widely Accepted and Successful" in Klaus J Hopt and Felix Steffek (eds) Mediation: Principles And Regulation In Comparative Perspective (Oxford University Press, Oxford, 2013) 1095.

31 "About AMINZ" Arbitrators' And Mediators' Institute Of New Zealand Inc <www.aminz.org.nz>.

32 European Union Directive No 2008/52/EC, discussed in Manon Schonewille and Jeremy Lack "Mediation in the European Union and Abroad: 60 States Divided by a Common Word?" in Manon Schonewille and Fred Schonewille (eds) The Variegated Landscape of Mediation: A Comparative Study of Mediation Regulation and Practices in Europe and the World (Eleven International Publishing, The Hague, 2013) at 19: "... all states in the EU have adopted the Directive. The purpose of the Directive was to create minimum common rules on mediation for all members States of the EU in cross-border civil and commercial mediation with the exception of Denmark."

33 The Directive did not clarify whether "mediation was a clearly understood process, or whether it may have varied in practice from country to country and if so, how": Schonewille and Lack, above n 32, at 20.

34 United Nations Commission on International Trade Law UNCITRAL Model Law on International Commercial Conciliation with Guide to Enactment and Use (United Nations, 2002) at 10. Such proceedings might be referred to as "conciliation, mediation, neutral evaluation, mini-trial or similar terms" (at 11). By 2012, the World Bank Group study Investing Across Borders found that of 100 economies surveyed, institutions providing mediation or conciliation services existed in 80. Sixty-four surveyed states reported having laws providing for court referral of commercial cases to mediation or conciliation; 46 had enacted some kind of law addressing out-of-court mediation or conciliation. See "Investing Across Borders: Indicators of Foreign Direct Investment Regulation" World Bank <www.iab.worldbank.org>. 
Yet the establishment of legal and institutional structures for mediation does not signify, nor does it necessarily promote, widespread use of mediation. The fact is, "modern" mediation has taken broad root in some places and failed to broadly germinate in others. In many places around the world the promotion and burgeoning of a "supply side" has yet to be met with discernible demand. ${ }^{35}$

A 2014 study, suggestively titled "Rebooting" the Mediation Directive, concludes that despite the passage of legislation and the development of an "ADR Movement" fuelling the creation "of new mediation centres, publications, conferences and trainings", the 2008 European Union Directive on Mediation "has not achieved its objective of ... promot[ing] the amicable settlement of disputes by encouraging the use of mediation and by ensuring a balanced relationship between mediation and legal proceedings". ${ }^{36}$ Although a single outlier, Italy, which mandates that parties sit down for a "preliminary" meeting with a mediator (at no cost) before litigating, claims over 200,000 mediated cases annually, almost half (46 per cent) of European Union countries reported less than 500 mediated cases, and only three (the United Kingdom, Germany and the Netherlands) claimed more than $10,000 .^{37}$

Take the case of Austria, which has been described as "one of the first movers in the field of mediation". ${ }^{38}$ Austrian mediation has been the subject of a fairly comprehensive regulatory framework since a 2004 Act established a national Advisory Council for Mediation at the Ministry of Justice, established requirements for listing on the register of mediators, set requirements for training institutes and courses, promulgated rights and duties for registered mediators, and other matters. ${ }^{39}$ As of 2012, 2,377 mediators were registered in Austria. ${ }^{40}$ However, in 2013 it was reported that only 500 to 2000 mediations were occurring annually. ${ }^{41}$

35 See text accompanying n 228

36 The Austrian Act on Mediation in Civil Matters (Bundesgesetz über Mediation in Zivilrechtssachen, Zivilrechts-Mediations-Gesetz) came into effect in 2004. See European Parliament Directorate-General for Internal Policies "Rebooting" the Mediation Directive: Assessing the Limited Impact of Its Implementation and Proposing Measures to Increase the Number of Mediations in the EU (Policy Department C: Citizens' Rights and Constitutional Affairs, 2014) ["Rebooting" the Mediation Directive] at 6. The study was conducted by a group led by Italian mediator and trainer Giuseppe De Palo, a long-time proponent of mediation in the EU.

37 "Rebooting" the Mediation Directive, above n 36, at 6.

38 Christoph Leon and Irina Rohracher "Austria" in Giuseppe De Palo and Mary B Trevor (eds) EU Mediation: Law and Practice (Oxford University Press, Oxford, 2012) 11 at 18.

39 "Rebooting" the Mediation Directive, above n 36, at 17.

40 At 20.

41 At 6. 
Even in Germany, which reported more than 10,000 cases annually, ${ }^{42}$ "mediation has led a quite shadowy existence ... and has not yet become a significant part of the legal landscape". ${ }^{43}$ However, proponents anticipate that the enactment of a new Mediation Code in 2012, which established a regulatory structure for mediation in domestic and international cases, may stimulate changes through greater public awareness and appreciation of mediation. ${ }^{44}$

Thus, although mediation is an increasingly visible part of the landscape of international commercial disputes, ${ }^{45}$ it has not achieved the status it enjoys in the United States. A study published in June 2010 under the auspices of the European Commission indicated that on average, mediation was only being employed in about 0.5 per cent of litigated cases in Europe. ${ }^{46}$

In the 2013 Queen Mary survey of selected international corporate counsel in the financial services, energy and construction arenas, mediation actually ranked below arbitration and court litigation as a preferred dispute resolution mechanism. ${ }^{47}$

However, the landscape is shifting and the very existence of a vocal and growing "evangelical" base for mediation may itself bring about a tipping point. Again, the 2011 Fortune 1,000 survey of corporate counsel indicates that leading international corporations are very favourable to the use of mediation. ${ }^{48}$ The International Mediation Institute now proselytises and offers a form of credentialing on a global scale, as well as a form of user feedback. Long-standing institutional proponents of international commercial arbitration like the International Chamber of Commerce (ICC) have placed increasing emphasis on mediation; the ICC now sponsors a high-profile

42 At 6.

43 Renate Dendorfer-Ditges and Ulla Gläßer "Germany" in Manon Schonewille and Fred Schonewille (eds) The Variegated Landscape of Mediation: A Comparative Study of Mediation Regulation and Practices in Europe and the World (Eleven International Publishing, The Hague, 2013) 167.

44 Renate Dendorfer-Ditges "Germany" in Renate Dendorfer-Ditges (ed) Getting the Deal Through (Law Business Research Ltd, London, 2013) at 35-41.

45 Queen Mary University of London and PricewaterhouseCoopers International arbitration: Corporate attitudes and practices (2006) at 5 (44 per cent of respondents preferred to resolve cross-border disputes utilising international arbitration and other ADR approaches; another 16 per cent preferred using mediation and other ADR)

46 Schonewille and Lack, above n 32, at 20.

47 Queen Mary University of London and PricewaterhouseCoopers Corporate choices in International Arbitration: Industry perspectives (2013) at 6. However, this picture may be somewhat misleading from the standpoint that in some countries or cultures conciliation or mediation come into play during arbitration, with arbitrators sometimes making active efforts to spur settlement. See Thomas J Stipanowich and Zachary P Ulrich "Commercial Arbitration and Settlement: Empirical Insights into the Roles Arbitrators Play" (2014) 6 Penn State Yearbook on Arbitration and Mediation 1 at 25-28.

48 Stipanowich and Lamare, above n 12, at 18. 
international mediation competition for law students, and a mediation analogue of the Vis International Commercial Arbitration Competition is being organised. Just recently, preparations have been made for an UNCITRAL Working Group to explore the creation of a Convention on the Enforcement of Mediated Settlements, an international platform for the enforcement of mediated agreements intended to mimic the role played by the New York Convention in the international enforcement and recognition of binding arbitration awards. ${ }^{49}$ Would-be leaders in the global dispute resolution market, such as Singapore, are touting new and improved brands of international mediation. ${ }^{50}$ Its proponents undoubtedly hope that such a platform will boost commercial mediation - domestic and international - into overdrive.

Whatever one's views on these developments, the mounting global hubbub surrounding mediation, and highly varied perceptions regarding the nature and value of mediation, underscore the need for thoughtful conversation and deliberate reflection on present trends and tendencies. The failure to periodically step back and take stock of where we are and where we are going increases the likelihood of behavioural "drift" - that is, action that becomes increasingly reflexive as opposed to deliberate. ${ }^{51}$

The following discussion briefly touches on three general areas of inquiry, each of which is intended to surface present challenges as well as opportunities.

\section{A The Diverse Evolution of Mediation in a Global Society}

Mediation practice and the surrounding regulatory framework is evolving in diverse ways, reflecting not only the individual experience and personalities of participants but also the influence of the marketplace (which often means the legal marketplace), the role of culture, and the interplay between mediation and systems of adjudication. These realities prompt questions such as the following:

49 Refer to United Nations Commission on International Trade Law, Working Group II (Arbitration and Conciliation) Settlement of commercial disputes: Enforceability of settlement agreements resulting from international commercial conciliation/mediation - Revision of the UNCITRAL Notes on Organizing Arbitral Proceedings: Comments received from States: Note by the Secretariat A/CN.9/WG.II/WP.188 (2014). Major initiatives are underway to bring mediation into play in the resolution of investor-state disputes. For example, IMI is currently at work on a set of standards for investor-state mediators: "Investor-State Mediation Task Force" International Mediation Institute <www.imimediation.org>.

50 See Ministry of Law Singapore "Commercial Dispute Resolution Services in Singapore Set to Grow" (press release, 3 December 2013): "The Ministry of Law ... welcomes recommendations made by the International Commercial Mediation Working Group ... to develop Singapore into a centre for international commercial mediation."

51 See generally Stipanowich, above n 1; and Stipanowich, above n 2 (discussing examples of "drift" in commercial arbitration practice). 
- What do we expect from "mediation", and what techniques and approaches do mediators employ in the course of fulfilling their roles?

- In what ways do legal advisors affect the usage and format of mediation, and what questions do the answers raise regarding the relative roles of lawyer and client?

- Why has "modern" mediation been broadly embraced in some cultures and systems but not others?

- How is mediation perceived to differ from conciliation, and what are the implications of such a dichotomy?

- What is the appropriate relationship between the activities of mediators and adjudicators?

- As greater reliance is placed on mediation in the resolution of domestic and international disputes, what, if any, impact will there be on the rendition of justice (from the standpoint of perceived fairness or effectiveness of the process, and the result, cost and time-savings, and other parameters)?

\section{B The Impact of Technology, Empirical Study and Institutionalisation}

Along with globalisation, a number of important "trends" appear to be at work in shaping the course of mediation or augmenting our understanding of mediation processes. Relevant questions include:

- What will be the impact on mediation of present mega-trends such as the revolution in information technology?

- How might insights from studies in brain science and cognition, masses of available electronic data, and other empirical "deep dives" shape our understanding and use of mediation?

- How, if at all, should mediators be professionally qualified and identified to potential users?

\section{Moving Upstream}

The popularity and the widening experience base with mediation has encouraged efforts to apply the same skills and insights in relational settings in advance of the ripening of disputes, the hardening of positions and the engagement of legal advocates. In light of the great and growing challenges facing society, it is appropriate to consider the possibilities of "moving upstream" to promote conflict competence and relational communication and collaboration. Put as a question:

- How can mediation be more effectively employed not just to resolve legal disputes, but to sustain and improve relationships between persons, within and between organisations, and between countries and regions? 
In the pages below, I will briefly touch on each of the foregoing subjects and advance these questions more fully.

\section{DIVERSE MODES OF MEDIATION IN A GLOBAL SOCIETY}

\section{A The Many Ways We Mediate}

Since the earliest days of the Quiet Revolution there has been unending discussion and debate about the roles of mediators and the techniques they employ. At times, the argument is framed in terms of what does or does not qualify as proper "mediation". 52

Hoping to chart the evolving territory of mediation practice and provide a framework for reflection and discussion, Professor Len Riskin conceived his vaunted "grid", identifying a spectrum of mediator approaches differentiating "facilitative" from "evaluative" techniques, and another spectrum distinguishing "narrow" emphases (focusing on the issues in dispute, party positions and the likely disposition of the dispute in the absence of a negotiated settlement) and "broad" emphases (embracing concerns about underlying party interests, needs and other factors). ${ }^{53}$ Riskin has continued to tinker with his grid, reflecting the more nuanced insights borne of continuing experience and deliberation. ${ }^{54}$ For present purposes, several points are particularly important. First of all, we know from United States practice that it is common for mediators not to adhere to a single approach but respond dynamically to the circumstances; in other words, they "move around the grid" during the course of a single mediation. (As one successful mediator vividly remarked, "I am facilitative in the morning and evaluative in the afternoon." $)^{55}$ Secondly, as reflected in a recent study from Europe, there is growing appreciation of the fact that mediators' activities are directed not only at substantive discussions but at process management, ${ }^{56}$ both are critical elements of the recipe for resolution, and mediators' approaches to both these elements will vary depending on mediator styles or strategies. ${ }^{57}$ Finally, it appears that some mediators' approaches often mirror

52 Sabine Walsh "When Mediation isn't Mediation At All" (July 2014) Mediate.com: Mediators \& Everything Mediation <www.mediate.com>.

53 Leonard L Riskin "Understanding Mediators' Orientations, Strategies, and Techniques: A Grid for the Perplexed" (1997) 1 Harv Negot L Rev 7.

54 Leonard L Riskin "Decisionmaking in Mediation: The New Old Grid and the New New Grid System" (2003) 79 Notre Dame L Rev 1.

55 This reality was evident in many comments by respondents to the recent IAM/Straus Institute Survey. See text accompanying n 63, below. See also Kiser, above n 12, at 213-216, discussing evaluative mediation, and perspectives that mediators tend not to provide evaluations unless it is requested or the parties are at impasse.

56 Schonewille and Lack, above n 32, at 25-35.

57 Mediators who tend to be more assertive with regard to substantive issues are not necessarily more assertive when it comes to matters of process, as exemplified by data from the IAM/Straus Institute Survey. For 
individual style or character traits, and that some successful mediators are sought out precisely because they are known for handling cases in a particular way. ${ }^{58}$ That said, there are good reasons to think that most mediators best serve the parties and process by using approaches reflectively and strategically - that is, as a deliberate response to specific circumstances and expectations. ${ }^{59}$

Our understanding of what mediators do, and how, when and why they do it, rests heavily on anecdote - the individual, personal experiences of mediators and other participants as expressed in their writings, speeches or teaching. ${ }^{60}$ The lack of a broader vantage point limits our ability to appreciate how individual experiences compare to many others, and how regional or national patterns may vary. The recent IAM/Straus Institute Survey ${ }^{61}$ represents one of a number of efforts to expand our understanding of practices and perceptions among experienced mediators, and to help contribute to a baseline for deeper research and discussion. ${ }^{62}$

Not surprisingly, the theme of individual commitment to flexibility and dynamism was evident in many of the comments of mediators in the IAM/Straus Institute Survey. Questions seeking information about the extent to which mediators embraced particular practices in mediation were met with comments like the following: "[My approach is] highly case-specific[: a] function of party preferences." "I consider all alternatives ... and tailor to the situation." "The mediation process must remain fluid and flexible." "There is no skill, strategy or tactic ... that I haven't used." As one respondent put it most succinctly, echoing the mantra of Straus Institute training: "It depends." ${ }^{3}$

example, the Survey data suggest that, although mediators practising in California tend to be more likely to offer substantive evaluations than mediators elsewhere, they are less likely to police unethical behaviour by attorneys in mediation: see IAM/Straus Institute Survey, above n 21.

58 See generally Sam Glover "How to Pick a Mediation Style" (13 March 2015) Lawyerist <www.lawyerist.com>; Jeff Kichaven "How to Pick a Mediator" (October 2007) Mediate.com: Mediators \& Everything Mediation <www.mediate.com>; and Alaska Judicial Council "Five Steps to Choosing a Qualified Mediator" (August, 1998) Mediate.com: Mediators \& Everything Mediation <www.mediate.com>.

59 See for example Marjorie Aaron and Dwight Golann "Merits Barriers: Evaluation and Decision Analysis" in Dwight Golann Mediating Legal Disputes: Effective Strategies for Neutrals and Advocates (American Bar Association, Chicago, 2009) 145 at 145-162 (discussing if, when and how mediators might offer evaluations).

60 There are, however, a growing number of studies examining the "what, where, when, how and why" of mediation practice. For example, see text accompanying notes 21,36 and 47 , above.

61 IAM/Straus Institute Survey, above n 21.

62 For a brief summary of forms of empirical research relating to mediation, see below at Part III: B: Insights of Cognitive Psychology, Data Mining and Other Empirical "Deep-Diving" at 1228.

63 Emphasis added. 
However, the Survey also obtained considerable information regarding the tendencies or "default preferences" of these experienced mediators with respect to many different elements of the process, and thereby surfaced a diverse spectrum of practices. Nowhere was the variety of approaches more evident than in the case of mediators' relative employment of joint sessions (in which the mediator engages parties and counsel in the same room) and caucus (in which the mediator meets separately with each party). As shown on the first line of Figure 1 ("All responding mediators"), some mediators responding to the Survey (39.7 per cent) always or usually begin the mediation with all parties in separate rooms (caucus). However, the data indicate that even more mediators begin mediation with a joint session.

Figure 1: IAM/Straus Institute Survey of Mediator Practices and Perceptions (2014)

"I begin the mediation with all parties in caucus."

Comparison of Responses by Regions of Practice

\begin{tabular}{|c|c|c|c|c|c|c|}
\hline & $\begin{array}{l}\text { Never } \\
\text { (0) }\end{array}$ & $\begin{array}{l}\text { Sometimes } \\
\text { (1) }\end{array}$ & $\begin{array}{l}\text { About half } \\
\text { the time } \\
\text { (2) }\end{array}$ & $\begin{array}{c}\text { Usually } \\
\text { (3) }\end{array}$ & $\begin{array}{c}\text { Always } \\
\text { (4) }\end{array}$ & $\begin{array}{l}\text { Weighted } \\
\text { average }^{64}\end{array}$ \\
\hline All responding mediators & $\begin{array}{c}21.4 \% \\
(27)\end{array}$ & $\begin{array}{l}35.7 \% \\
(45)\end{array}$ & $\begin{array}{c}3.2 \% \\
(4)\end{array}$ & $\begin{array}{c}25.4 \% \\
(32)\end{array}$ & $\begin{array}{c}14.3 \% \\
(18)\end{array}$ & 1.75 \\
\hline $\begin{array}{l}\text { Mediators practising in } \\
\text { United States }\end{array}$ & $\begin{array}{c}17.2 \% \\
(16)\end{array}$ & $\begin{array}{c}37.6 \% \\
(35)\end{array}$ & $\begin{array}{c}3.2 \% \\
(3)\end{array}$ & $\begin{array}{c}30.1 \% \\
(28)\end{array}$ & $\begin{array}{c}11.8 \% \\
(11)\end{array}$ & 1.82 \\
\hline $\begin{array}{l}\text { Mediators practising in } \\
\text { California }\end{array}$ & $\begin{array}{l}14.0 \% \\
(6)\end{array}$ & $\begin{array}{l}32.6 \% \\
(14)\end{array}$ & $\begin{array}{c}0.0 \% \\
(0)\end{array}$ & $\begin{array}{l}34.9 \% \\
(15)\end{array}$ & $\begin{array}{c}18.6 \% \\
(8)\end{array}$ & 2.12 \\
\hline $\begin{array}{l}\text { United States mediators } \\
\text { practising outside } \\
\text { California }\end{array}$ & $\begin{array}{c}19.4 \% \\
(12)\end{array}$ & $\begin{array}{c}38.7 \% \\
(24)\end{array}$ & $\begin{array}{c}4.8 \% \\
(3)\end{array}$ & $\begin{array}{c}27.4 \% \\
(17)\end{array}$ & $\begin{array}{c}9.7 \% \\
(6)\end{array}$ & 1.69 \\
\hline $\begin{array}{l}\text { Mediators practising } \\
\text { outside United States }\end{array}$ & $\begin{array}{c}37.8 \% \\
(14)\end{array}$ & $\begin{array}{c}27.0 \% \\
(10)\end{array}$ & $\begin{array}{l}2.7 \% \\
(1)\end{array}$ & $\begin{array}{c}13.5 \% \\
(5)\end{array}$ & $\begin{array}{l}18.9 \% \\
(7)\end{array}$ & 1.24 \\
\hline
\end{tabular}

Even more interesting, however, are the group results when sorted by regions of practice (Figure 1). These data suggest that, while mediators practising in each region show great diversity in their approaches to the use of caucuses, there are also noticeable differences in the overall response from region to region. Survey data suggest, for example, that mediators practising in California tend to be more likely than other groups to begin mediation with the parties in caucus; mediators practising

64 The weighted averages were obtained by assigning values to each of the response categories ("Never" $=0$; "Sometimes" = 1 and so forth through "Always" = 4), multiplying the number of respondents in each category by that coefficient, adding all the results and dividing by the total number of respondents to obtain an average value for the group. 
outside the United States collectively tend to be much less likely to do so. Mediators practising in the United States, but outside California, tend to fall somewhere in the middle in their approaches. These data should be read with the firm caveat that the groupings of "mediators practising [in states] outside California" and "mediators practising outside the United States" were made largely for the sake of convenience, ${ }^{65}$ and it is not unlikely that, given a larger global pool of respondents, a further breakdown by state or region would highlight other differences not apparent from the data as currently configured. As discussed above, moreover, there also appears to be wide diversity of practice within any group. ${ }^{66}$

Nevertheless, the regional divergence reflected in Figure 1 bears consideration, particularly since similar patterns are reflected in a number of other group responses to Survey queries. For example, other data from the Survey indicate that about one-quarter ( 24.6 per cent) of all mediators responding to the Survey always or usually keep parties in caucus during the entire mediation; a slightly greater number (29.4 per cent) never do so. Paralleling the patterns revealed in Figure 1, mediators practising in California are more likely to keep parties in caucus throughout mediation, mediators practising outside the United States are much less likely to do so, and mediators practising in the United States but outside California tend to fall somewhere in between the other groups. ${ }^{67}$

A similar regional divergence was reflected with regard to how mediators handle information received from parties in caucus. The overall response was again broadly diverse: some respondents tend to tell parties that all information shared during caucus will be confidential unless they instruct the mediator to share it, others tend to tell parties that they will share any information learned during caucus with the other party as they see appropriate, unless instructed not to share it. Interestingly, respondents practising outside the United States are more likely to take the former approach and California mediators the latter approach; once again, mediators practising in other parts of the United States tend to fall somewhere in between. The pattern might cause one to wonder if there is a relationship between the degree of emphasis on separating the parties during mediation and the propensity - or need - to have more flexibility in the sharing of information imparted in caucus. ${ }^{68}$

65 California mediators represented almost a third of the respondents, but other regions or jurisdictions are represented by smaller numbers - sometimes only one or two individuals. This reality is an obstacle to obtaining meaningful results from further breakdowns and comparisons of the present data by region or jurisdiction.

66 In regards to the use of joint sessions versus caucuses in mediation, Randall Kiser's study of experienced United States advocates found decidedly mixed views among interviewees, with "some regarding joint sessions as highly beneficial and others contending they were inflammatory": Kiser, above n 12, at 209.

67 See IAM/Straus Institute Survey, above n 21.

68 See IAM/Straus Institute Survey, above n 21. 
A final area of divergence was, perhaps not surprisingly, in the realm of mediator evaluation and opinion-giving. Although many United States mediators were first taught that they should respect party autonomy by avoiding any expressions of opinion regarding the issues in dispute or the prospects for recovery in court, ${ }^{69}$ many of these same mediators soon found themselves offering evaluations at some stage of mediation, and parties often actively sought such input. ${ }^{70}$ Indeed, a 1991 survey capturing specific mediation experiences of United States construction attorneys indicated a statistically significant correlation between mediator evaluation and settlement. ${ }^{71}$ Given the strong representation of United States practitioners in the current Survey, it is perhaps not surprising that 80 per cent of respondents indicated that their reputation as a mediator who can offer useful assessments of parties' cases was a factor of some importance in attracting and maintaining clients. ${ }^{72}$ However, there are distinct regional differences in responses to related queries. The data indicate that, generally speaking, mediators outside the United States tend to be much more likely than their California counterparts to "help parties develop, consider, and/or communicate proposal that may lead to settlement, but ... not offer [their] own opinion regarding these proposals" ${ }^{73}$ Conversely, mediators practising in California are much more likely to "develop and propose potential agreements the parties might all accept as part of a potential settlement", to "tell parties [their] predictions of how not settling might affect them, including what [they] think may result if the case proceeds to court or arbitration", or "assess, and share [their] opinion regarding, the legal strength of arguments made by parties and/or counsel". ${ }^{74}$

In summarising the results of the Survey, one must take care not to overstate the degree of divergence among mediators practising in different places. In many ways patterns of practice do not appear to vary greatly among regions, and there appear to be some areas of general convergence or, more accurately, similar spectra of mediator behaviours. For example, just as experienced arbitrators are coming to grips with the need to set the stage for the arbitration process through

69 This was true of the author's own initial mediation training in 1991.

70 See for example Thomas J Stipanowich "The Multi-Door Contract and Other Possibilities" (1998) 13 Ohio St J on Disp Resol 303 at 367 (discussing trends in the mediation of construction disputes).

71 Thomas J Stipanowich "Beyond Arbitration: Innovation and Evolution in the United States Construction Industry" (1996) 31 Wake Forest L Rev 65 at 123 (in reports of individual construction mediation, "[t]here were significantly more ... settlements in cases in which mediators expressed views on pertinent facts or law").

72 See IAM/Straus Institute Survey, above n 21.

73 Emphasis added.

74 See IAM/Straus Institute Survey, above n 21. Kiser's study of experienced advocates also delved deeply into the use of evaluation by mediators, and surfaced significant disparities in attitudes regarding mediator

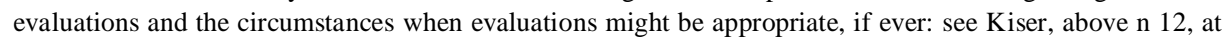
213-216. 
carefully planned prehearing conferences, ${ }^{75}$ this group of experienced mediators tend to place great emphasis on preliminary preparation before the actual mediation session(s). ${ }^{76}$ In addition to developing a picture of the issues in dispute, they may familiarise themselves with the history of negotiation, the "temperature" of the parties and key personalities at play. They may work with counsel to lay the groundwork for an appropriate mediation process, including the agenda for initial joint sessions and the tentative timing and even the planned duration of caucuses. There appears to be pervasive appreciation of the importance of forward preparation in mediation. ${ }^{77}$

Nevertheless, other recent data reinforce the theme of divergence among cultures and legal systems. In their excellent critique of emerging mediation systems in the European Union, Manon Schonewille and Jeremy Lack concluded: ${ }^{78}$

$[T]$ here are no predictable legal frameworks or guidelines for parties coming from different countries as to how mediation should be initiated or overseen. There are no clear EU guidelines or provisions regarding mediator quality standards, or clear explanations about what different forms of mediation may mean. Each member state has been left free to develop a culturally-shaped and nationally biased view of what the word "mediation" means, without creating any bridges between these different interpretations, and there are a dizzying number of different practices and definitions existing today, not only within the EU but across the world as a whole.

Significantly, they conclude: ${ }^{79}$

[The appropriate] solution is not to impose one definition or prescribe one approach to mediation, but to facilitate the use of commercial and civil mediation across borders by enabling parties and their counsel to understand the different options that exist so they can make an informed choice.

When it comes to the use of consensual dispute resolution processes that may be flexibly tailored to a wide variety of circumstances, this is sound advice.

However, in cultures in which there is a bias toward professional regulation, the temptation may be to anticipate the development of mediation by formulating a legal framework for mediation that is idiosyncratic and that, at worst, undermines flexibility and predictability in the management of

75 See IAM/Straus Institute Survey, above n 21.

76 See IAM/Straus Institute Survey, above n 21.

77 See IAM/Straus Institute Survey, above n 21. See also Bennett G Picker "Preparation: The Key To Mediation Success" (March 2010) Mediate.com: Mediators \& Everything Mediation <www.mediate.com>; and David Laufer "How to Prepare for Mediation: The Mediator's Check List Of Key Legal And Factual Issues" (September 2007) Mediate.com: Mediators \& Everything Mediation <www.mediate.com>.

78 Schonewille and Lack, above n 32, at 20.

79 At 21. Compare Thomas J Stipanowich "Arbitration and Choice: Taking Charge of the 'New Litigation' (Symposium Keynote Presentation)" (2009) 7 DePaul Bus \& Comm LJ 383. 
conflict. For example, although "[m]ediation is still incipient in Brazil,"80 the Brazilian National Congress recently passed a fairly extensive Mediation Act that regulates many aspects of mediation. ${ }^{81}$ Those contemplating mediation in Brazil should be aware of, and take counsel regarding the importance of, provisions of the Act that: (1) establish detailed requirements for contractual mediation provisions, including "minimum and maximum period for the completion of the first mediation meeting", the site of mediation, "criteria for choice of mediator", and "penalty in the event of non-attendance of the party invited to the first meeting of mediation"; 82 (2) make a distinction between mediation and conciliation, thus raising questions regarding the ability of mediators to engage in evaluation; ${ }^{83}$ (3) legally prohibit mediators from serving as arbitrators or judges in the same dispute; ${ }^{84}$ (4) provide for the establishment of judicial (court-connected) mediation centres, and state that mediators designated from those centres for cases are not subject to prior acceptance by the parties (absent conflicts of interest); ${ }^{85}$ and (5) state that "information

80 Diego Faleck "Brazil" in Renate Dendorfer-Ditges (ed) Getting the Deal Through (Law Business Research Ltd, London, 2013) at 21.

81 Presidency of the Republic [of Brazil] Civil House, Assistant Deputy for Legal Affairs, Law 13.140, of 26 June 2015. English Translation by Marcio Vasconcellos (on file with author).

82 Article 22. Although the parties may, alternatively, make contractual reference to rules of "a reputable institution providing mediation services" there is still a requirement for "clear criteria for the choice of the mediator and the holding of the first mediation meeting".

83 Article 24. By making the distinction, the Brazilian law raises questions about whether mediators may engage in any form of evaluation. See below Part D: Interplay between Mediation, Adjudication and the Broader Ends of the Legal System at 1221. According to Brazilian scholars, "[t]he preliminary hearing has among its main objectives the attempt at reconciliation, a goal that, in addition to eliminating the conflict more quickly and without much expense, makes possible the restoration of peaceful coexistence between the parties": Luiz Guilherme Marinoni and Sergio Cruz Arenhart Processo de Conhecimento (8th ed, Editora Revista dos Tribunais, Sao Paulo, 2010) at 247. However, the Brazilian Mediation Act defines mediation in art 1 as "the technical activity carried out by an impartial third party without decision-making power, which, chosen or accepted by the parties, assists and encourages them to identify or develop consensual solutions to the dispute" (emphasis added). This raises questions as to whether arbitrators or judges should be allowed to mediate; whether a mediator is allowed to provide his/her opinion on the merits of the case; and how arbitrators and judges are encouraged to conciliate in a preliminary hearing if they are not allowed to mediate.

84 Article 7. Although the practice of serving in more than one role in the course of resolving a single dispute is controversial in the United States and some other cultures and legal systems, an outright legal prohibition on mixed roles is much more intrusive than the approach of leaving the matter to agreement. See text accompanying n 170 , below.

85 Article 25. 
provided by a party in a private session [caucus] will be confidential, and the mediator cannot reveal it to others, except as expressly authorized". 86

\section{$B$ Lawyers and Mediation}

In the United States and many other countries, lawyers serve as gatekeepers for the justice system, and as such play a leading, often determinative role in the selection and shaping of processes for resolving disputes. From the beginnings of the Quiet Revolution, United States mediation has been heavily influenced by the choices and concerns of legal advocates. There are indications that the same is true in regards to the development of mediation in other countries.

Some United States proponents of mediation first envisioned it as a game-changing vehicle capable of giving disputants a primary role in resolving their own conflict, repairing broken relationships, promoting interest-based solutions, and even opening up the justice system by engaging people from different disciplines and community sectors as mediators. ${ }^{87}$ To the extent mediation has fallen short of such early expectations (at least in the realm of civil disputes) some point the finger at legal advocates. Peter Adler, a consultant with deep roots in the modern history of United States mediation, recently conducted an informal survey of mediators he knew personally or by reputation and found that, although their stories were an interweaving of the good and the bad, there was a group sense that mediation had largely devolved into a game of numbers, or positional bargaining - lawyers had gradually established "hegemony, a takeover of the mediation work and a slow but steady disenfranchisement of non-lawyers". ${ }^{88}$ Although there are many positive aspects to the continuing, evolving relationship between lawyers and mediation, there is concern among some mediators about the potential for lawyers to frame and dominate the process, game the system, limit the mediator's role and control communications ${ }^{89}$ - at worst, turning mediation into a mere whistlestop on the litigation line.

Given the inherent flexibility of mediation and the critical importance of maintaining clear lines of communication and good relationships between project team members during the course of a project, it seemed natural that mediators might be able to step in early for the purpose of helping nip conflict in the bud, fostering better communications and strengthening relational ties. Sometimes

86 Article 31. Practices among mediators regarding the communication of information gleaned in caucus vary widely. The approach embraced by the Brazilian law is more limiting of the flexibility of the mediator. See text accompanying $n$ 68, above.

87 Stipanowich, above $\mathrm{n} 9$, at 13 .

88 Peter S Adler "Expectation and Regret: A Look Back at How Mediation Has Fared in the U.S." (paper presented to 7th National Conference of the Civil Mediation Council, London, May 2013) at 5.

89 At 6-7. 
this happens. ${ }^{90}$ From early days, however, the bulk of "commercial" mediation disputes tended to focus rather on settling cases along the road to trial or arbitration. From the beginning, mediation usually came about after - often long after - the parties had "lawyered up" and positions had hardened. It was usually prompted by a court or by attorneys. ${ }^{91}$ The mediator was nearly always a lawyer, and sometimes a retired judge. ${ }^{92}$ And sooner or later the process nearly always got down to the hard slogging: the back-and-forth of distributive bargaining resulting in a monetary settlement. ${ }^{93}$ As mediation has become settled practice, a trend reinforced by established custom, and by the inclusion of mediation as an element in stepped contractual dispute resolution provisions, the early patterns have continued. ${ }^{94}$ The difference is that most litigators now have garnered extensive experience with mediation and with a wide variety of mediators. They may use these insights in a variety of ways. They may work strategically with the mediator by, for example, providing helpful information about the dynamics of the dispute and the personalities of the participants, and by ensuring that the negotiation "dance" proceeds in a way that best protects their client's interest while exploring trade offs and, occasionally, options for value creation. ${ }^{95}$ While it is expected that some

90 See text accompanying n 263, below. See also James G Zack Jr (ed) Delivering Dispute Free Construction Projects: Part II - Construction \& Claim Management (Navigant Construction Forum, March 2014) at 32 (noting that mediation is always in an option in resolving job claims and disputes); and Stipanowich, above $\mathrm{n} 70$, at 368-369 (discussing successful example of use of standing mediator on public project).

91 See Stipanowich, above n 71, at 111, table J (65 per cent of reported cases involved mediation by postdispute agreement of the parties; about 29 per cent were mediated pursuant to a court order or court rules).

92 See at 116 , table $\mathrm{O}$ (64.5 per cent of mediators in reported cases were attorneys; 21.1 per cent were retired judges).

93 See at 120, table R (the vast majority of settlements (298 out of 315 cases) involved money; a much smaller percentage resulted in an agreement to perform certain work (32 out of 315); and only a handful of cases produced other outcomes from settlement).

94 More than nine-tenths of respondents to the recent IAM/Straus Institute Survey (90.6 per cent) had practised as litigation attorneys and more than a tenth (11.1 per cent) had served as a judge. Only 10 individuals (8.5 per cent of respondents) lacked legal experience: IAM/Straus Institute Survey, above n 21. There is an ongoing debate about the impact of legal experience on an individual's qualifications as a mediator: see Cris Currie "Should a Mediator Also Be An Attorney?" (August 2000) Mediate.com: Mediators \& Everything Mediation <www.mediate.com>. It has been suggested that because there are currently few licensing or regulatory schemes for mediators in the United States, a legal or judicial background may operate as a de facto qualification for being considered a competent mediator: James Grifo "An Argument for the Establishment of Professional Standards and Increased Regulation of the Practice of Mediation" (September 2012) Mediate.com: Mediators \& Everything Mediation <www.mediate.com>. See for example Kiser,

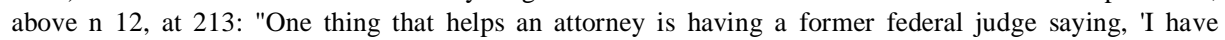
overseen 3,000 cases.' They tell plaintiffs about how they've seen plaintiffs with good cases get nothing and how defendants with good defenses got hit with huge verdicts."

95 An excellent discussion of advocacy during mediation may be found in Dwight Golann "Advocacy at Specific Stages" in Dwight Golann Mediating Legal Disputes: Effective Strategies for Neutrals and Advocates (American Bar Association, Chicago, 2009) 255. 
degree of manipulation will occur as attorneys withhold information or mask intentions from the mediator $^{96}$ (just as mediators manipulate the process and parties in various ways, consciously or unconsciously), ${ }^{97}$ mediators believe the process generally works. More than three-quarters (76.7 per cent) of respondents to the IAM/Straus Institute Survey of experienced mediators viewed the increasing familiarity of counsel with the mediation process as a positive development. ${ }^{98}$ There are indications that these experienced mediators' generally favourable attitude regarding the role of lawyers in mediation is reflected by the perspectives of experienced United States advocates toward mediation. ${ }^{99}$

On the other hand, attorneys may contribute to mediation dysfunction by actively misleading the mediator regarding the prospects for settlement and ensuring that the day of resolution is postponed in order for the litigation train to proceed through full discovery. ${ }^{100}$ The vast majority $(84.2$ per cent) of respondents to the IAM/Straus Institute Survey indicated that attorneys at least sometimes use mediation as a means of continuing the litigation process with no intent to settle. ${ }^{101}$ While counsel may not be faulted for wanting to have material information in hand before concluding a settlement, this does not mean that full discovery is necessary; indeed, a skilful mediator may be able to help the parties identify and target priorities for information exchange.

Counsel sometimes employ mediation for the sole purpose of obtaining information regarding the opposition's case. ${ }^{102}$ Moreover, according to Peter Adler, mediators are expressing growing concern about lawyers taking control of the mediation process, limiting joint sessions ${ }^{103}$ and insisting that all communications go directly through them. ${ }^{104}$ Such tactics appear to be particularly

96 See Nick C Nichols "Mediation: Should You Tip Your Hand? Stonewall? Or Just Show Up?" (paper presented at the Kentucky Academy of Trial Lawyers Annual Convention and Seminar, September 2002).

97 See Jim Coben and Lela P Love "Trick or Treat: The Ethics of Mediator Manipulation" ABA Dispute Resolution Magazine (United States of America, Fall 2010).

98 See IAM/Straus Institute Survey, above n 21.

99 See Kiser, above n 12, at 216: "The study attorneys were generally enthusiastic about mediation, although some expressed concerns it was being misused for discovery purposes."

100 Susan Nauss Exon Advanced Guide for Mediators (LexisNexis, New Providence, 2014) at 71-72.

101 See IAM/Straus Institute Survey, above n 21. See also Kiser, above n 12, at 216, quoting an experienced advocate as saying that mediation "has become totally abused by insurance companies ... [which] use it to make the process more expensive and drag things out."

102 Kiser, above n 12, at 216: "The study attorneys were generally enthusiastic about mediation, although some expressed concerns it was being misused for discovery purposes."

103 Adler, above n 88, at 7. See also Kiser, above n 12, at 209, among various perspectives, quoting an advocate as stating: "Joint sessions are a goddamn waste of time. The lawyers are trying to convince clients they're determined and completely committed. It's like two male dogs - who's going to back down." 
common - or at least especially discernible - in California, and may be an important contributing factor in the tendency of California mediators, discussed above, to limit joint sessions and rely relatively heavily on caucus. As one California respondent to the IAM/Straus Institute Survey put it: 105

In California, counsel seem to have taken over the mediation process, and it is just not possible to have a pure mediation where the parties engage directly. On occasion, I have been specifically instructed that counsel and the parties do not even need to see each other.

The United States experience suggests that as attorneys garner more and more experience with mediation in the course of resolving civil disputes, they are likely to play more assertive roles in shaping the process. ${ }^{106}$ One might think, moreover, that familiarity with the dynamics of mediation would equip attorneys with the skills and understanding to more successfully engage in direct negotiations with their counterparts, thereby lessening the need for third party intervention. There is, however, evidence to suggest that over-reliance on mediation has made some United States litigators less comfortable engaging in direct negotiation, and even fearing that such communications would be interpreted as showing a lack of confidence in their case. ${ }^{107}$ There have also been concerns expressed about the impact of diminished rates of trial on the ability of young lawyers to assess their own chances in court. ${ }^{108}$ There are also concerns about the wholesale rush of retirees from the bench and bar, along with some active practitioners, into the practice of mediation. ${ }^{109} \mathrm{In}$ sum, it is clear that as mediation becomes an important element of a justice system and related law practice, lawyers have a significant impact - exert their own kind of "gravitational pull" - on mediation; conversely, mediation changes the practice of law. These are important topics for our future dialogue and reflection.

Meanwhile, there is evidence that lawyers are also influencing the development of mediation which in some cases means retarding its development - in other places. For example, summaries of perspectives collected at an IMI-inspired international Convention on Shaping the Future of

104 Adler, above n 88, at 7. See also Kiser, above n 12, at 211, quoting an advocate as explaining: "I don't want the mediator asking my client questions directly. Clients may give up something early."

105 Another California-based respondent commented, "In Los Angeles the lawyers control the process and the legal personalities can be difficult. These same lawyers, and others, refuse joint sessions."

106 See generally Kiser, above n 12, reflecting a variety of strong opinions and strategies on the part of experienced advocates in regards to mediation.

107 See at 204-207, discussing experienced advocates' perceptions of how mediation has caused many attorneys to be uncomfortable engaging in direct negotiations with the other side or confronting their client with the prospects of success or failure for their case.

108 See at 216

109 See at 217. 
International Dispute Resolution in London in 2014 offer strong indications that, while many business users tend to favour the use of mediation early in the life of disputes, their external counsel are much less enthusiastic. ${ }^{110}$ Over three-quarters of business users attending the Convention registered support for early resort to mediation, while less than half (44 per cent) of legal advisors agreed. Two-thirds of users supported the use of dispute resolution provisions that required mediation prior to arbitration or litigation, but only 16 per cent of advisors took that view. Most users also supported permitting courts to mandate the use of mediation (66 per cent), but again, only a small percentage of advisors (16 per cent) agreed. ${ }^{111}$ In a related vein, there were also significant disparities when it came to perceptions of the need to reduce costs and risks in international dispute resolution - goals often tied to alternative dispute resolution (ADR) and to mediation; while twothirds of users ranked these as paramount factors in international dispute resolution, outside advisors placed more emphasis on focusing on key issues. Tellingly, many business users conceded that the ineffective use of ADR was attributable to the failure of in-house counsel and senior management to effectively express their needs to outside counsel. ${ }^{112}$ Once again, these data reflect the important of more meaningful discussion and deliberate choice-making by clients and counsel.

\section{The Impact of Culture and Legal Systems}

The IAM/Straus Institute Survey illustrates that the diversity of mediation practice appears to be tangibly reinforced by regional differences that may reflect differences in systems of law or national or local cultures, ${ }^{113}$ a conclusion strongly reinforced by international comparisons. ${ }^{114}$ As society becomes increasingly global, parties and counsel are likely to be drawn into conflict with

110 See Deborah Masucci and Michael Leathes "The urgent need for data: are the needs of users and the dispute resolution market misaligned?" (November 2013) Mediate.com: Mediators \& Everything Mediation <www.mediate.com>.

111 Masucci and Leathes, above n 110.

112 Masucci and Leathes, above n 110. IMI is now organising a Global Pound Conference Series that will test this data and explore emerging trends relating to the use of various dispute resolution processes in several cities around the world: see "Global Pound Conference Series" Global Pound Conference <www.globalpoundconference.org>.

113 Even within the boundaries of the United States, as discussed above, there appear to be different regional tendencies among experienced mediators. See text accompanying n 65 and n 66, above. This may be at least partly a reflection of the strong regional cultures that underpin values, perceptions and practices in different parts of North America: see generally Colin Woodward America's Nations: A History of the Eleven Rival Regional Cultures of North America (Penguin, New York, 2011), tracing the origins and evolution of discrete "national" cultures within the United States, Canada and northern Mexico.

114 See Schonewille and Lack, above n 32, at 21. 
international partners, thus entering territory that is more likely to be unfamiliar in many respects to those acclimated to domestic practice. ${ }^{115}$

There is no question that the United States "modern mediation" model and variants developed in places like the United Kingdom and Australia have been very influential throughout the world. ${ }^{116}$ As with religion and other conceptual exports, however, there is always the matter of translation into cultures that sometimes have much older traditions of mediation, as in Asia. In "relearning mediation from the West", as Singapore Professor Joel Lee explains, Asian mediators have a challenge in translating a Western mediation approach founded on the primacy and autonomy of individuals and the furtherance of individual interests, with a traditional orientation toward, among other things, social hierarchy, societal harmony and obedience to authority. ${ }^{117}$ The challenge might include not only figuring out what techniques and approaches mediators should employ, but also embracing the very notion that a mediator might be an independent paid professional, as opposed to an adjudicator or other authority figure.

An outstanding illustration of this phenomenon is China, where mediation, or "conciliation", 18 has a rich and venerable history dating back more than two millennia. Submitting disputes to a "wise counsellor" - a village elder or authority figure - for the purpose of promoting or restoring harmony was consistent with Confucian precepts, ${ }^{119}$ and the practice remains an important mechanism for

115 See generally Schonewille and Lack, above n 32. See also Michael McIlwrath and John Savage International Arbitration and Mediation: A Practice Guide (Kluwer Law International, Alphen aan den Rijn, 2010); and Jean-Claude Goldsmith, Arnold Ingen-Housz and Gerald H Pointon (eds) $A D R$ in Business: Practice and Issues across Countries and Cultures (Kluwer Law International, Alphen aan den Rijn, 2006).

116 Joel Lee "Culture and Its Importance in Mediation" (draft article) (on file with the author) at 7.

117 See generally Lee, above n 116.

118 Although it is possible to discern differences in the usage of the two terms, they generally are used interchangeably: Sally A Harpole "The Combination of Conciliation with Arbitration in the People's Republic of China" (2007) 24 J Int'l Arb 623; and Carlos de Vera "Arbitrating Harmony: 'Med-Arb' and the Confluence of Culture and Rule of Law in the Resolution of International Commercial Disputes in China" (2004) 18 Colum J Asian L 149 at 152. There is some historical support for defining conciliation as a process in which the third party would prepare and propose an agreement that he or she viewed as representing a fair settlement: Nigel Blackaby and others Law and Practice of International Commercial Arbitration (5th ed, Oxford University Press, New York, 2009) at 5. This model is consistent with traditional Chinese practice. See text accompanying n 122, below.

$119 \mathrm{Gu}$ Xuan "Discussion on the Combination of Arbitration and Mediation in China with a Developing Viewpoint" (Research Paper on Arbitration Law for Masters in Business Law, Université de Genève/Université de Lausanne, May 2008) at 20: "Traditionally, [Chinese dispute resolution] took the form of seeking out a respected elder who would impart wisdom, offer an evaluation of the situation, and provide solutions for the parties." 
maintaining the social order in the People's Republic of China, ${ }^{120}$ where traditional mediators are still sometimes referred to as "Old Uncle". ${ }^{121}$ However, mediation is practised in ways that are different from the broad run of "modern" mediation as practised in the United States, and mediation has normally been conducted by individuals who operate from a position of authority relative to the parties.

In the modern era, conciliation/mediation programmes (People's Conciliation Committees) operate in thousands of communities and urban neighbourhoods throughout China. ${ }^{122}$ Some years ago I had the opportunity to visit a People's Conciliation Committee in Beijing with a class of law and graduate students. Expecting to see a place with conference rooms in which parties would be brought together for facilitated negotiation, we instead found a mediation "office" furnished with a sole chair situated opposite the mediator's desk. On the wall above, a chart clearly showed the mediator's place in the hierarchy of local governmental officials. We had the privilege of meeting a woman who was introduced to us as one of the most successful community mediators in the People's Republic of China (PRC); our subsequent conversation left the impression that her normal method of resolving community disputes - usually clashes among neighbours regarding the use of common facilities, noise problems and the like - was to investigate, converse separately with those involved and propose a solution. In this role - which is much more directive than the norm for commercial or neighbourhood mediators in the United States, but well suited to keeping the peace in a densely-packed neighbourhood in a high-context culture and hierarchical society like the PRC she was very effective.

Mediation has also been "housed" within other loci of authority, notably institutions of public or private justice; the modern practice has been for adjudicators to engage in mediation prior to trial if the parties so agree. ${ }^{123}$ My students and I observed a civil court proceeding in Beijing relating to an action involving an auto accident in which, prior to taking evidence in the case, the judge asked the parties if they wished to have him mediate the dispute. ${ }^{124}$ Likewise, the rules of leading Chinese

120 Ananth Krishnan "China passes mediation law to aid strained judiciary" (30 August 2010) The Hindu <www.thehindu.com> ("'Mediation should be the first line of defence to maintain social stability and promote harmony,' Minister of Justice Wu Aiying told the National People's Congress Standing Committee.").

121 Ying Wang "Why Not Have E-Mediation in China?" (unpublished paper, Straus Institute for Dispute Resolution, 2015) (on file with author).

122 As of 2009, there were in excess of 823,000 People's Mediation Committees and 4.9 million mediators in the programmes: State Council White Paper: Progress in China's Human Rights in 2009 (2009).

123 Chinese law provides for court mediation where the parties agree: provisions of the Supreme People's Court on Several Issues Concerning the Civil Mediation in the People's Courts (Fa Shi [2004] No 12). See generally Thomas J Stipanowich and others "East Meets West: An International Dialogue on Mediation and Med-Arb in the United States and China" (2009) 9 Pepp Disp Resol LJ 379.

124 The parties did not wish to mediate, so the case proceeded to trial. 
institutions sponsoring private arbitration provide that if the parties so agree, arbitrators may try to informally resolve the dispute prior to rendering a decision on the merits. ${ }^{125}$ These approaches tend to be far different from the mainstream of modern mediation in the United States, where the practice of mediation by third parties who are insulated from the judicial process is underpinned by prevailing concerns about preserving party autonomy in mediation and the integrity of judicial decision making. ${ }^{126}$

As the PRC evolved into a first-tier commercial trading nation, it sent signals to prospective partners that it would promote the use of mediation in the resolution of disputes between Chinese and foreign entities. One government agency, the China Council for Promotion of International Trade (CCPIT), established partnerships with dispute resolution organisations in other countries for the purpose of developing joint mediation procedures for the resolution of international disputes. ${ }^{127}$ These frameworks - including the US-China Business Mediation Center, co-sponsored with the New York-based CPR Institute for Dispute Resolution ${ }^{128}$ - were developed independently of established structures such as Chinese community programmes, courts or recognised arbitration institutions. The US-China Business Mediation Center was conceived along the lines of a Western model, and sponsored a panel that included experienced Western mediators. However, there was no indication that the Center attracted much cross-border business despite various promotional efforts, leading me to assign the cause to the lack of experience in the PRC with comparable mediation models.

In 2008, the Straus Institute was invited to assist in the development and promotion of a "standalone" mediation programme at the Beijing Arbitration Commission (BAC), which sponsored 40hour basic mediation training (using an adaptation of the Straus "Mediating the Litigated Case" model) for dozens of Chinese lawyers, judges and arbitrators. ${ }^{129}$ BAC thereafter published mediation rules and established a multi-national panel of mediators. ${ }^{130}$ While the energy and

125 See for example Beijing Arbitration Commission Arbitration Rules, art 38; and China International Economic and Trade Arbitration Commission Arbitration Rules, art 47 (effective as of 1 January 2015).

126 See Stipanowich, above n 123, at 385-388.

127 See for example Zhang Jin "Joint mediation centre launched" (8 December 2004) China Daily <www.chinadaily.com.cn>, describing the 2004 creation of a mediation centre by CCPIT and the Italian Foreign Trade Commission, as well as past centres created and expansion possibilities.

128 CCPIT approached the author, who was then President and CEO of CPR (now known as the International Institute for Conflict Prevention \& Resolution) about establishing the programme that came to be known as the US-China Business Mediation Center.

129 The programme was the inspiration of Wang Hongsong, then Secretary General of BAC. As Vice Chairman of the BAC, Wang Hongsong retains a leading role in the development of domestic and international commercial mediation and dispute resolution in the PRC.

130 See Stipanowich, above n 123, at 379-380. 
reputation of the BAC created an unprecedented opportunity for the development of a new kind of framework for mediation in China, there were still questions about whether the notion of mediation as a free-standing process would catch on. ${ }^{131}$ In the wake of the publication of the new mediation procedures, I had occasion to communicate with a Chinese colleague who informed me that the mediation training through the BAC programme had been very beneficial, and that the insights were very useful in promoting settlement. I was given the impression, however, that these tools were being employed in the traditional way - that is, where an appointed arbitrator "switched hats" to mediate at the request of parties ("arb-med"), rather than by a mediator in a free-standing process. ${ }^{132}$

Mediation-within-arbitration, or arb-med, appears to be very much alive and well in the PRC. A survey in 2011 to 2012 of a selection of 100 active Chinese arbitrators sitting on the panels of CIETAC (the Chinese International Economic and Trade Arbitration Commission) and BAC netted 36 completed responses regarding perspectives and practices regarding arb-med, ${ }^{133}$ providing some basic insights into arbitrators' activities as mediators and the level of their commitment to the concept of mixed roles. Almost two-thirds (63.4 per cent) of responding arbitrators said they "almost always" or "often" employed caucuses during mediation; they "ha[d] no hesitation in meeting parties privately" as long as both parties agreed. ${ }^{134}$ Moreover, 80.6 per cent said that, when they engaged in mediation, they used what they considered evaluative techniques as well as facilitative approaches, ${ }^{135}$ including "mak[ing an] analysis of the strengths and weaknesses of each party's position" and discussing the risks of an arbitrated outcome. ${ }^{136}$ The great majority (almost 90 per cent) said they would at least sometimes offer a settlement proposal at the parties' request, with 25 per cent giving proposals frequently. ${ }^{137}$ On the other hand, nearly all respondents (97.3 per cent) asserted that they rarely or never expressed opinions on the merits of the case since, generally

131 See at $385-386$.

132 In 2010, 272 cases accepted by BAC, or 17.2 per cent of the total caseload, were settled by mediationwithin-arbitration, or arb-med. In 2011, the percentage of cases settled by arb-med was 18.45 per cent: see Fan Kun "An Empirical Study of Arbitrators Acting as Mediators in China" (2014) 15 Cardozo J Conflict Resol 777 at 793, citing Beijing Arbitration Commission Working Report (2010); and Beijing Arbitration Commission Working Report (2011). Elsewhere, Professor Fan Kun notes that the line between adjudicative and mediative functions have historically been blurred in Chinese minds. The role of an elder in the family, clan, village or guild, was not equivalent to that of either a mediator or an arbitrator, but rather incorporated both elements: see Fan Kun "Globalization of Arbitration: Transnational Standards Struggling with Local Norms Through the Lens of Arbitration Transplantation in China" (2013) 18 Harv Negot L Rev 175 at 193 207.

133 See Kun "An Empirical Study of Arbitrators Acting as Mediators in China", above n 132, at 788.

134 At 796.

135 At 796

136 At 799-800.

137 At 798 
speaking, that would be viewed as undermining their impartiality. ${ }^{138}$ Expressing confidence in arbmed, more than 80 per cent of the Chinese arbitrators expressed a belief that the model would be accepted and embraced in other countries. ${ }^{139}$

The public counterpart of arb-med, mediation by judges, is also proceeding apace, and has received renewed emphasis from the Chinese Government, which is offering strong incentives for its use. ${ }^{140}$ Curiously, a recent empirical study of 20 cases mediated in a provincial court revealed a system that departed in many ways from the arb-med model employed by arbitrators. Judicial mediation routinely occurred on the heels of the adjudicative hearing (consisting of the inquisitorial court investigation and court-supervised discussion) and private caucuses with the parties were not permitted ${ }^{141}$ at times, the process elements ran together. ${ }^{142}$

Currently, however, it appears that rapid change may be afoot in China. Thanks to a publication sponsored by BAC, Commercial Dispute Resolution in China: An Annual Review and Preview, ${ }^{143}$ accounts of current developments concerning mediation of business-to-business disputes (as well as some business-employee and business-consumer disputes) are accessible in English. From such sources it appears that efforts are occurring on a broad front, at least on the organisation level; active parties include the Peoples' Courts, BAC and other arbitration commissions, CCPIT, a Chinese National People's Mediators Association, academic institutions, industry associations and national corporations. ${ }^{144}$ The new Beijing Mediation Alliance, aimed at "explor[ing] the methods of cooperation between the mediation organisations, courts and governments", involves a network of 16 organisations that reflect the establishment of discrete mediation entities associated with the Internet, intellectual property disputes, securities and commodities futures, banking and financial

138 At 797.

139 At 800

140 Kwai Hang Ng and Xin He "Internal Contradictions of Judicial Mediation in China" (2014) 39 Law \& Soc Inquiry 285 at 286.

141 At 297.

142 At 296. The academic observers were very critical of the system, which they viewed as unsatisfactorily mixing formal fact finding and adversary process with supervised bargaining, and relying heavily on judicial leverage - or coercion - to bring about a settlement.

143 The second edition of this important English summary was published in 2014. See Wu Jun "Annual Review on Commercial Mediation" in Beijing Arbitration Commission Commercial Dispute Resolution in China: An Annual Review and Preview (Beijing Arbitration Commission, Beijing, 2014) at 44. The Author notes that a 2015 Review was released after the preparation of this article. It provides additional information and statistics. See Yan Yang and Hua Zhang "Annual Review on Commercial Mediation in China" in Beijing Arbitration Commission Commercial Dispute Resolution in China: An Annual Review and Preview (Beijing Arbitration Commission, Beijing, 2015) at 2.

144 See generally Jun, above n 143 . 
services, health care and entertainment. ${ }^{145}$ A southern counterpart of the Beijing network is the Commercial Mediation Alliance between the Guandong, Hong Kong and Macao Regions, headquartered in the Shenzhen International Court of Arbitration. ${ }^{146}$

All of a sudden, a wave of new mediation centres is appearing on the scene, offering new panels of freshly-minted mediators. The Beijing-based Mediation Center of [the] China Legal Advice Center, established in early 2014, aims to provide mediation services to resolve a wide array of commercial disputes between Chinese and foreign parties with a multi-disciplinary panel composed of "famous domestic experts and scholars in various disciplines of law, ... retired judges, prosecutors and lawyers who have rich experience in practice, and influential entrepreneurs in the relevant profession". ${ }^{147}$ Several months later, a group of institutions in Wenzhou created a system of "mediation tribunals" to address employment disputes within the financial services sector; "full or part-time experienced arbitrators" were to be assigned "to cope with the work in these financial mediation tribunals". ${ }^{148}$ Shortly thereafter, the Shenzhen Mediation Center on Disputes of [the] Securities and Futures Industry opened its doors for the purpose of "closely integrat[ing] mediation and arbitration for the capital market in China" through an "independent mediation mechanism" using professionals from the securities, futures and fund industries as well as law professors, arbitrators and lawyers with relevant experience. ${ }^{149}$ Even more recently, mediation programmes were established to help resolve intellectual property disputes arising in Free Trade Zones. ${ }^{150}$ In addition, growing concerns over online piracy led China's Ministry of Industry and Information Technology to establish a centre for mediation to address online copyright disputes. ${ }^{151}$

The People's Courts are also taking steps. Recently, some courts established court-connected programmes for the mediation of insurance disputes, with special provisions for legal recognition and enforcement of certified mediated agreements. ${ }^{152}$ In addition, some courts have recognised the authority of an independent body, the Mediation Center of the Internet Society of China, to mediate

145 At 45 .

146 At 46-47.

147 At $47-48$

148 At 48

149 At $48-49$.

150 At 49-50.

151 Catherine Shu "Chinese Government to Open Mediation Center for Online Piracy Disputes" (22 January 2013) Tech Crunch <www.techcrunch.com>

152 Jun, above n 143, at 52-53. When it comes to court-connected mediation in China, a driving force for its use is the government's commitment to a "socialist harmonious society"; settlement rate is one criterion for assessment of a judge's performance: see Carl Minzner "China's Turn Against Law" (2011) 59 Am J Comp L 2 . 
domain name disputes. ${ }^{153}$ Even more importantly, it appears that courts are prepared to accord broader recognition to the concept of mediation before selected third parties in cases coming into the court system. For example, the People's Court of Hangzhou West Lake District, Zhejiang Province, established a website for filing a case online and setting the stage for mediation facilitated by third party mediators, including lawyers, psychologists and other eligible people. ${ }^{154}$ Parties bringing cases to the court are referred to the website.

Even more significant, ultimately, may be developments associated with the expanding use of the Internet in the PRC, which has stimulated resort to online mediation. The growing use of online dispute resolution in China is discussed below. ${ }^{155}$

Within the last couple of years, China has also made major strides toward establishing programmes for advanced training in mediation skills and university degree programmes offering degrees in mediation. ${ }^{156}$ The CCPIT has redoubled its efforts to promote international commercial arbitration, ${ }^{157}$ and there are ongoing outreach efforts to dispute resolution bodies and educational institutions in other parts of the world. ${ }^{158}$

The extraordinary, unprecedented level of activity leading to the creation of a complex institutional network committed to the development of mediation in China might be taken to mean that China is moving in the direction of embracing new models of mediation that look more familiar to Westerners. However, information about what is going on in these new processes remains very limited. Although serious efforts are being made to understand and draw lessons from appropriate models from the United States and elsewhere, there are also indications that, as was the case with arb-med, traditional customs and models remain strong in the PRC.

In his thoughtfully prepared 2014 summary, Professor Wu offered descriptions of three completed mediations; all were successful on various levels - all three ended in a mediated agreement, and in two cases parties moved forward with their relationships. ${ }^{159}$ At the same time, the summaries of these mediated cases raise interesting questions about the dynamics of the processes,

153 This is an active mediation centre that handles Internet-related disputes. For example, in 2014, 2,044 cases in relation to Internet intellectual property infringement were accepted by the centre: see Yang and Zhang, above $\mathrm{n} 143$.

154 Hangzhou Xihu District People's Court Online Mediation (Chen Liaomin Justice Online Studio) <www.xfclm.com>.

155 See text accompanying $n$ 201, below.

156 Jun, above n 143 , at 50-51.

157 At $54-55$.

158 At $58-61$.

159 At 64-67. 
the interplay between the mediator and the court, the relative confidentiality of the mediation process and mediator assertiveness. In one of the two cases "commissioned" by a court, a highprofile dispute among four international record companies, it appears that both the appointed mediator and a "judicial panel" were actively engaged throughout the mediation process, with the judicial panel apparently meeting and offering interpretations to the parties along the way. ${ }^{160}$ In another court-ordered mediation, the process was apparently recorded in transcripts as well as an agreement, suggesting that the mediation was not a confidential process. ${ }^{161}$ In the third case, the mediator achieved a resolution by "patiently persuading both parties by explaining the facts according to the actual situation of the parties" - what sounds like a very traditional directive approach. ${ }^{162}$

There is now heightened interest among Chinese scholars and other interested parties in better understanding the dynamics of mediation and the ends served by such processes. ${ }^{163}$ This affords new opportunities for important issues like the priorities and goals served by mediation, the interplay between adjudication and mediation, the confidentiality of the mediation process and the techniques employed by mediators, to be addressed, and for mutual lessons to be learned, through thoughtful study and dialogue among practitioners and scholars with diverse cultural and systemic perspectives.

\section{$D$ Interplay between Mediation, Adjudication and the Broader Ends of the Legal System}

As the foregoing discussion reveals, different cultures and legal systems embrace contrasting views about the interplay between facilitation of a settlement and adjudication. As we have seen, the extent to which mediators offer substantive opinions regarding issues in dispute, or evaluations of a case's chances in court or arbitration, appears to be a major area of divergence among different world regions. ${ }^{164}$ Although many American commercial mediators tend to be comfortable engaging in evaluation, mediators from some other countries view such activities as beyond the scope of their role and incompatible in some respects with the concept of mediation as a "facilitated" process. ${ }^{165}$

160 At $64-66$.

161 At 66 .

162 At 67.

163 See at 67-71. See also at 47 (describing the research functions of the Mediation Center of the China Legal Advice Center in Beijing).

164 See text accompanying n 73 and n 74, above.

165 See for example Nicholas Gould, Claire King and Philip Britton Mediating Construction Disputes: An Evaluation of Existing Practice (Centre of Construction Law \& Dispute Resolution, King's College London, 2010) at 5-6, discussing distinctions made in the United Kingdom between mediation and conciliation. 
This disparity was reflected in data from the IAM/Straus Institute Survey, discussed above. ${ }^{166}$ The situation is dynamic, however, and there are indications that commercial mediators in different countries are employing evaluative or directive approaches along with more facilitative techniques. ${ }^{167}$

Conversely (and one might argue, from a United States perspective, paradoxically), dispute resolution professionals from some other jurisdictions may be more comfortable than United States counterparts with judges or arbitrators acting in the capacity of a mediator during the course of adjudication, ${ }^{168}$ and perhaps rendering nonbinding evaluations of parties' cases (which is sometimes referred to as "conciliation", although this term is often used interchangeably with mediation). ${ }^{169}$ As discussed above, the intermingling of adjudicative and mediative functions in a single individual, common in China, is not generally favoured in the United States ${ }^{170}$ (although it appears that a

166 See text accompanying $n 73$ and n 74, above.

167 See for example Michael Beckett "Mediation in Hong Kong" (presentation at CILS International Mediation Symposium, Salzburg, Austria, June 2015) (on file with author) ("Facilitative mediation is most widely taught, promoted and supported style in [Hong Kong, but a r] ecent survey showed that the belief of parties is that evaluative mediators add more value to a mediation as they can test the counter-party's case."); Alessandro Bruni and Michela Sitzia "Italy" in Renate Dendorfer-Ditges (ed) Getting the Deal Through (Law Business Research Ltd, London, 2013) 49 at 52 ("The primary mediation style for commercial mediation is 'facilitative' and, if the mediator thinks it to be opportune, or if the parties require it, the style may change to 'evaluative'."); Faleck, above n 80, at 19 ("Facilitative mediation in commercial cases is preferred and strongly advocated in Brazil. Mediators, however, may use evaluative methods at times, depending on their personal style."); Donald Lambert and others "England \& Wales" in Getting the Deal Through 28 at 31 ("The general approach of mediators in the UK is facilitative, focusing on the parties' interests rather than providing any substantive advice or opinion. There are, however, a wide range of approaches to mediation and if the mediator is or has been an advocate, they are more likely to take a more interventionist approach by advising parties privately on their opinion as to the merits of the case and chances of success."); Christoph Leon and Magdalena Heigl "Austria" in Getting the Deal Through 5 at 7 (In Austria, "mediation style depends mostly the clients. A mediator decides which kind of style he will use after the pre-mediation phase or during the main arbitration phase."); and Martin Maisner and Milos Olik "Czech Republic" in Getting the Deal Through 22 at 24 (different mediation styles are used; facilitative and transformative approaches predominate, although lawyer mediators are more likely to use evaluative approaches). In Switzerland, the Rules of Commercial Mediation of the Swiss Chambers of Commerce define mediation as being distinct from conciliation: "Mediation is an alternative method of dispute resolution whereby two or more parties ask a neutral third party, the mediator, to assist them in settling a dispute or in avoiding future conflicts. The mediator facilitates the exchange of opinions between the parties and encourages them to explore solutions that are acceptable to all the participants. Unlike an expert the mediator does not offer his or her own views nor make proposals like a conciliator, and unlike an arbitrator he or she does not render an award" (emphasis added).

168 See text accompanying n 132, above.

169 See Gould, King and Britton, above n 165, at 5-6. See also Centre for Effective Dispute Resolution CEDR Commission on Settlement in International Arbitration, Final Report (November 2009) [CEDR Commission Report].

170 See Stipanowich and Ulrich, above n 47, at 25-28. 
sizeable minority of experienced American dispute resolution professionals have experience with mixed roles) ${ }^{171}$ and some other countries. ${ }^{172}$ In jurisdictions where the practice of mediators changing hats to arbitrate or adjudicate is frowned upon, permitting arbitrators or judges to "conciliate" is arguably inconsistent - a form of cognitive dissonance. As one Brazilian advocate observes: $:^{173}$

Although there is no formal prohibition that mediators act later as arbitrators, there is consensus in the

ADR Brazilian community that this is not a convenient practice, for the sake of information exchange

and the effectiveness of the process. State judges, however, often act as conciliators. This is widely

criticized by professionals and academics. They fear that conciliation from judges may have an

intimidating effect on the parties.

Setting aside the matter of mixed roles, it is clear that the growing emphasis on mediation and the phenomenon of increasing rates of settlement during the course of arbitration, prior to the rendition of an award or even prior to hearing, are creating new opportunities for dialogue regarding the ways in which mediation and arbitration may be intertwined in practice. ${ }^{174}$ It might, for example, lead to greater appreciation of both sides of the debate over the propriety of dispute resolution professionals serving in multiple roles, and, perhaps, more sophisticated handling of such scenarios. ${ }^{175}$

More broadly speaking, there are various ways the adjudicative backdrop for mediation may influence the timing, character and outcome of mediation. The very notion that a matter may be submitted to disposition by a public or private tribunal creates expectations that will factor in the decisions of parties - the timing and amount of settlement - expectations that are often influenced

171 See Thomas J Stipanowich and Zachary P Ulrich "Arbitration in Evolution: Current Practices and Perspectives of Experienced Commercial Arbitrators" (2014) 25 Am Rev of Int'l Arb 395 at 463-465.

172 See for example Johan Billet and Dilyara Nigmatullina "Belgium" in Renate Dendorfer-Ditges (ed) Getting the Deal Through (Law Business Research Ltd, London, 2013) at 11 ("No cases are known where a mediator would have acted in the same dispute as an arbitrator or judge. The rules of arbitration and mediation institutes would hardly foresee such a possibility."); and Leon and Heigl, at 167, at 5 ("A mediator is not allowed to act later in the same dispute as an arbitrator, conciliator or judge.").

173 See Faleck, above n 80, at 18.

174 At 29.

175 One result might be a set of protocols aimed at mediators who, having not yet facilitated a complete settlement of a dispute, are asked to switch to the role of arbitrator. See for example Thomas J Stipanowich and Peter H Kaskell (eds) Commercial Arbitration at Its Best: Successful Strategies for Business Users (CPR Institute for Dispute Resolution, 2001) at 22-30, presenting an early model of such a protocol. The IMI, the US College of Commercial Arbitrators and the Straus Institute for Dispute Resolution are organising an International Task Force on Combined Processes that will seek to establish wide-ranging guidelines for these scenarios. The author is one of the chairs. 
by actors' risk or loss-aversion ${ }^{176}$ as well as the perceived possible costs and benefits of adjudication. It is here that predictive evaluations come into play in United States mediation and, in some countries, when judges or arbitrators engage in conciliation. Along the way, the calculus of when and how to settle may be affected by the actions adjudicators take - or are likely to take - on motions for summary judgment or the early disposition of claim, defences or procedural issues; or decisions ordering the disclosure of certain evidence. ${ }^{177}$ On multiple levels, then, the outcome or range of likely outcomes in mediation is frequently a function of the broader adjudicative framework.

Today, many commercial contracts call for mediation to be employed as a stage in a multiphased dispute resolution procedure (perhaps as the intermediate step in a three-stage process beginning with negotiation and culminating, if necessary, in some form of adjudication). ${ }^{178}$ Stepped provisions are a straightforward response to the reality that most disputes are amenable to a negotiated settlement, and to the benefits of early, informal resolution. ${ }^{179}$ Where direct negotiation between representatives of the parties is unavailing, the intervention of a mediator may help break the logjam and craft a workable resolution. ${ }^{180}$ But the linear arrangement of elements in multi-stage dispute resolution templates does not take account of the reality that dispute resolution is very often "non-linear". For a variety of reasons, it may be thought impossible or impracticable to settle a case before the filing of a court complaint or an arbitration demand. ${ }^{181}$ Lawyers or parties may have differing expectations about the likely outcome of a pending adjudication, ${ }^{182}$ or may believe they have insufficient information to settle. ${ }^{183}$ Decisions about whether and when to settle may be clouded by the desire to avoid a perceived loss; the tendency to seek confirmation of biases brought to litigation; the notion that it is always better to have more information; and concerns about

176 Peter S Bauman "Loss Aversion in Settlement Negotiations" (4 January 2013) JD Supra Business Advisor <www.jdsupra.com>.

177 Stipanowich and Ulrich, above n 47, at 16.

178 At $8-10$.

179 Stipanowich and Kaskell, above n 175, at ch 1, discussing the importance of multi-tiered approaches for management of conflict and avoiding stand-alone arbitration provisions. See also CEDR Commission Report, above n 169, at [4.2.1], discussing benefits of multi-tier dispute resolution clauses.

180 Stipanowich and Kaskell, above n 175, at 11-14.

181 Stipanowich and Ulrich, above n 47 , at 9.

182 Andrew J Wistrich and Jeffrey J Rachlinski "How Lawyer's Intuitions Prolong Litigation" (2013) 86 So Cal L Rev 571 at 576; and Paul M Lurie "Using the guided choice process to reduce the cost of resolving construction disputes" (2014) 9 Constr L Int'1 18 at 21.

183 Wistrich and Rachlinski, above n 182; and Lurie, above n 182, at 20 
justifying previously spent dollars in litigating a case. ${ }^{184}$ In many such cases, mediation is postponed until shortly before hearings, when discovery is completed or well-advanced. ${ }^{185}$

There are, however, ways mediators can empower parties to come to grips with these realities. As process facilitators, mediators may help parties appreciate the influence of cognitive factors on negotiations using approaches such as Guided Choice. ${ }^{186}$ They may also facilitate parties' focus on key factual issues and focused information exchange, ${ }^{187}$ or targeted binding or nonbinding decisions by judges or arbitrators that could lay the groundwork for resolution of conflict. ${ }^{188}$ Even where substantive issues cannot be resolved in mediation, mediators may nevertheless focus on facilitating agreements regarding dispute resolution process elements and helping parties to set the stage for arbitration proceedings with features that are effectively tailored to the issues at hand. ${ }^{189}$

Finally, consideration of the interplay between mediation and adjudication must also include careful attention to the particular dynamics that may inhere when mediated settlements are given special status as enforceable agreements - a reality that is contemplated for international disputes by proponents of a current UNCITRAL initiative. ${ }^{190}$ For example, any regime for heightened international enforcement of mediated agreements must include some measures to prevent mediation being a cover for transactions intended to launder the proceeds of a crime or to finance terrorist organisations - concerns that are very real in the realm of international commerce. ${ }^{191}$ Moreover, the highly politicised debate over privatised forms of investor-state dispute settlement has surfaced concerns of wide sectors of the public regarding transparency, fairness and adherence

184 See generally Wistrich and Rachlinski, above n 182; and Lurie, above n 182. See also Randall Kiser Beyond Right and Wrong: The Power of Effective Decision Making for Attorneys and Clients (Springer, London, 2010) at 89-195, discussing "decision errors" by attorneys and related psychological and institutional factors.

185 See Lurie, above n 182, at 19, noting that "mediation is frequently seen as a tool to be used close to trial or an arbitration hearing as a hedge against an unfavorable judgment or award".

186 At 19-20. See also Paul Lurie and Jeremy Lack "Guided Choice Dispute Resolution Processes: Reducing the Time and Expense to Settlement" (2014) 8 DRI 167.

187 Stipanowich and Kaskell, above n 175, at 19.

188 Lurie, above n 182, at 20-21. Compare Wistrich and Rachlinski, above n 182, at 624-626.

189 Lurie, above n 182, at 19-20.

190 See United Nations Commission on International Trade Law Working Group II Settlement of commercial disputes - International commercial conciliation: enforceability of settlement agreements A/CN.9/WG.II/WP.190 (2015).

191 See Nigel Blackaby and others Redfern and Hunter on International Arbitration (5th ed, Oxford University Press, Oxford, 2009) at 338-341, discussing related concerns and countermeasures in the context of international arbitration. 
to the rule of law. ${ }^{192}$ In contemplating official treatment of agreements reached through mediation as a new form of "international super-contracts", we should consider: (1) the policy implications of giving broad legal recognition to outcomes from what may be a process that may be highly confidential and significantly more opaque than court hearings or even binding arbitration processes; including (2) the extent to which the interests of third-party stakeholders should be protected, (3) the implications for the operations of the legal system and the rule of law, and (4) the possible impact of the chosen process on the parties' behaviour and future ability to work collaboratively.

\section{THE IMPACT OF THE TECHNOLOGICAL REVOLUTION, EMPIRICAL STUDIES AND INSTITUTIONALISATION}

\section{A Technology, Mediation and Conflict Management}

In every aspect of our lives, communication is increasingly digital and virtual, and the implications for managing and resolving conflict are immense. In an age when clients demand greater value for money and rapid results, technology offers many opportunities for achieving efficiency and economy and, hopefully, providing fair and satisfactory experiences and outcomes. It also presents many new challenges.

As a primary means of communication across distances, and even within homes and offices, email has become an indispensable element in conflict and its resolution. Electronic interchange is the backbone of modern business transactions; therefore, students in my negotiations class regularly bargain online with students across the country, learning by experience the benefits, limitations and protocols of negotiation through electronic media. ${ }^{193}$ Email is also a prime ancillary tool for dispute resolution professionals in mediation and arbitration. ${ }^{194}$

Since the beginning of the 21 st century, a variety of existing and would-be dispute resolution service providers have promoted online dispute resolution (ODR) in the form of "cybermediation". ${ }^{195}$ Although growth was initially slow, ${ }^{196}$ ODR has found an initial and

192 See Don Lee "Critics of Trans-Pacific Partnership trade deal warn about arbitration clause" (19 August 2015) Los Angeles Times <www.latimes.com>; and Paul Rogerson "EU-US trade deal compromise ditches arbitration" (10 July 2015) The Law Society Gazette <www.lawgazette.co.uk>.

193 See Jay Folberg and Dwight Golann Lawyer Negotiation: Theory, Practice and Law (2nd ed, Kluwer Law International, Alphen aan den Rijn, 2011) at 165-180, discussing pros and cons of online negotiations.

194 See Thomas Schultz Information Technology and Arbitration: A Practitioner's Guide (Kluwer Law International, Alphen aan den Rijn, 2006) at 153-167.

195 John W Cooley Mediation Advocacy (2nd ed, LexisNexis and National Institute for Trial Advocacy, 2002) at 231 and 243 .

196 For example, in 2001, the CPR Institute (then headed by the author) partnered with a pioneering ODR organisation headed by Colin Rule and Dana Haviland to promote secure online platforms for negotiation 
expanding niche with the growth of e-commerce, as it proved to be a means of addressing concerns regarding the reliability of online sellers or products, and the availability of accessible recourse, in the event of a dispute. ${ }^{197}$

The cutting edge of online mediation is presently in the arena of high-volume, low-value online transactions. The most visible and notably successful of online systems is the one designed by SquareTrade as the ODR provider for eBay, a system that has facilitated the settlement of millions of disputes between online buyers and sellers. ${ }^{198}$

The advent of ODR prompted UNCITRAL to establish a Working Group to draft procedural rules on Online Dispute Resolution for Cross-Border Electronic Commerce Transactions (ODR For E-Commerce). ${ }^{199}$ While there are serious questions about the eventual outcome of this effort, ${ }^{200}$ change is proceeding apace. This is certainly the case in China, the home of more than 600 million Internet users (comprising almost half the population of the PRC as of the end of 2013). ${ }^{201}$

The Chinese Internet company, Sina, established a team of 5,000 mediators for its Weibo social media platform. ${ }^{202}$ Taobao, the Chinese counterpart of eBay, now sponsors its own equivalent of the ODR system designed by SquareTrade for eBay. ${ }^{203}$ In 2014, Baidu, the Chinese web-services corporation, established the Baidu People's Mediation Committee in order to properly respond to disputes from consumers and enterprises they link to through Baidu. ${ }^{204}$ As noted above, several Chinese courts authorised the Mediation Center of the Internet Society of China to mediate domain

and dispute resolution to dispute resolution professionals and attorneys; the experiment was not successful in attracting business, probably because the market was not yet ready.

197 Janice Nadler "Electronically Mediated Dispute Resolution and E-Commerce" in (2001) 17 Negotiation Journal 333 at 334-335.

198 Steve Abernethy Building Large-Scale Online Dispute Resolution \& Trustmark Systems (Proceedings of the UNECE Forum on ODR, 2003) (President and CEO of Square Trade, Steve Abernethy, discusses the enegotiation system designed for eBay).

199 See United Nations Commission on International Trade Law, Working Group III (Online Dispute Resolution) Online dispute resolution for cross-border electronic commerce transactions: Submission by Colombia and the United States of America: Note by the Secretariat A/CN.9/WG.III/XXXII/CRP.3 (2015).

200 Heather Scheiwe Kulp "Future Justice? Online Dispute Resolution and Access to Justice" (8 August 2011) Just Court ADR <blog.aboutrsi.org> ("With all the innovations in technology, I still wonder if technology can provide adequate legitimacy, quality and access to justice outside the court system.").

201 China Network Information Center Statistical Report on Internet Development in China (January 2014).

202 Tancent Tech "Taobao Processes 20,000 Disputes Daily" (18 November 2012) Marbridge Consulting $<$ www.marbridgeconsulting.com>.

203 See Tech, above n 202.

204 Jun, above n 143, at 56-57. 
name disputes. ${ }^{205}$ The Mediation Center of the Internet Society of China (ISC) has partnered with various institutions to promote new online dispute coordination and resolution mechanism for Internet-based claims. ${ }^{206}$ These developments suggest that mediation through online platforms represents a looming cutting edge of change for mediation of online transactions as well as courtconnected mediation in the PRC. It will be interesting to see how these changes affect perceptions and practices in Chinese mediation.

\section{B Insights of Cognitive Psychology, Data Mining ${ }^{207}$ and Other Empirical "Deep-Diving"}

Concepts from the realm of cognitive psychology such as risk aversion, anchoring, attribution error and reactive devaluation have recently become a part of the lexicon of negotiation and conflict management. ${ }^{208}$ As our sights are broadened by interaction on a global scale, experiments with cognition and the mining of "big data" have opened yet another frontier for exploration. We are being given new opportunities to reflect on the impact of our perceptions on lawyering and resolving conflict, ${ }^{209}$ and to glean new insights into group behaviours by analysing masses of information.

Thanks to the work of behavioural economists, neurobiologists and others, we are coming to understand that far from being engines of rationality, human beings operate subject to the dictates of mental processes that skew our perceptions and steer us onto unpredictable paths. ${ }^{210}$ In one way or another many of these insights are relevant to managing and resolving conflict through mediation.

205 Agreement on Authorizing Internet Society of China to Mediate Internet-Related Dispute Cases, Guangdong Province High People's Court.

206 See Jun, above n 143, at 56. See also Jingzhou Tao Arbitration Law and Practice in China (3rd ed, Kluwer Law International, Alphen aan den Rijn, 2012) at 243-251.

207 This section is adapted from Stipanowich, above n 1, at 391-392.

208 Exon, above n 100, at 62-72.

209 See generally Jennifer K Robbenholt and Jean R Sternlight Psychology for Lawyers: Understanding the Human Factors in Negotiation, Litigation and Decision Making (American Bar Association, Chicago, 2013).

210 See Dan Ariely Predictably Irrational: The Hidden Forces That Shape Our Decisions (Harper Collins, Oxford, 2008) (work on behavioural economics). New findings in neurobiology are also starting to influence process design and dispute resolution processes. The Interdisciplinary Centre for Affective Sciences (CISA) in Switzerland, a national research centre headed by Prof David Sander and Dr Olga Klimecki, has recently launched a five year research project to assess how recent discoveries in brain and social sciences can be used to improve dispute resolution and peacemaking processes: see "The Role of Emotions in Conflict Resolution" Affective Sciences: Swiss National Center of Competence in Research <www.affective-science.org>. 
Russell Korobkin and Chris Guthrie, among others, advanced our awareness of dynamics at the bargaining table. ${ }^{211}$

These insights are reinforced by the parsing and rigorous assessment of available data. Employing "neural networks, predictive modelling, and genetic algorithms", Donald Philbin isolated trends across groups of similar negotiations and within particular negotiations, and created Picture It Settled, web-based software that allows negotiators to "optimize their concession strategies and predict where a [bargaining] round will end". 212

Randall Kiser has used datasets from VerdictSearch California to offer in-depth analysis of decision making by lawyers during settlement negotiations. ${ }^{213}$ More recently, Kiser conducted indepth interviews with 78 leading trial attorneys from New York and California, producing a broad range of experience-based perspectives on mediation in the American civil justice system. ${ }^{214}$ Kiser's study of experienced lawyers illustrates how our growing body of experience with mediation has encouraged scholars, practitioners and institutions to study and, where possible, more accurately describe, measure or quantify various aspects of our perceptions of mediation. ${ }^{215}$ Some studies focus on the effectiveness of mediation for particular types of disputes; for example, a 2011 study of case assessment and mediation in the Michigan circuit courts found that tort cases were more likely to be referred to mediation than non-tort cases, and that tort cases referred to mediation resulted in settlement or consent judgment more often than non-tort cases referred to mediation. ${ }^{216}$ The gender and ethnicity of mediators is another common focus of scholarship. The differences, if any, between

211 See for example Russell B Korobkin and Chris Guthrie "Heuristics and Biases at the Bargaining Table" (2004) 87 Marquette L Rev 795; and Chris Guthrie and Dan Orr "Anchoring, Information, Expertise and Negotiation: New Insights from Meta-Analysis" (2006) 21 Ohio St J on Disp Resol 597. Neuroawareness, a San Diego-based company, is also offering a range of new products designed to assist lawyers, judges, arbitrators and mediators to incorporate teachings from the neurosciences into their practices and how they prepare for dispute resolution processes: see Neuroawareness <www.neuroawareness.com>.

212 "Panelist Profile: Philbin, Jr., Donald R" Conflict Solutions of Texas <www.csoftx.com>.

213 See generally Kiser, above n 184.

214 Kiser, above n 12, at 203.

215 Earlier meta-surveys of empirical research suggested that both the quality of extant research and the results are decidedly mixed: see Thomas J Stipanowich "ADR and the 'Vanishing Trial' The Growth and Impact of 'Alternative Dispute Resolution'" (2004) 1 Journal of Empirical Legal Studies 843 (summarising earlier studies of mediation and its operation in public and private settings, along with arbitration and other approaches); and Roselle Wissler "The Effect of Court-Connected Dispute Resolution in Civil Cases" (2004) 22 Conflict Res Quarterly 55 at 80.

216 See Teresa G Campbell and Sharon L Pizzuti The Effectiveness of Case Evaluations and Mediation in Michigan Circuit Courts: Report to the State Court Administrative Office, Michigan Supreme Court (October, 2011) at 6, 34 and 36-37. (Tort cases submitted to mediation resulted in settlement or consent judgment 92 per cent of the time, while non-tort cases achieved the same result through mediation only 77 per cent of the time.) 
male and female mediators have been studied for over 20 years, and while statistical differences have been found, the link between each gender and a particular mediation style appears hypothetical. ${ }^{217}$ Attention has also been given to the personal profiles of mediation participants. A study of small claims courts mediations found that the ethnicity, race and national origin of a mediation participant was less significant than the participant's gender; and all of these traits were found to be less significant to the mediation process than the socio-economic class of the participant(s). ${ }^{218}$ All of these efforts are aimed at a better understanding of the varying practices and perspectives of mediators and mediation participants; the IAM/Straus Institute Survey, ${ }^{219}$ described above, is another small step in that direction.

Not so long ago lawyers, judges, dispute resolution professionals, service providers, educators, systems designers and law and policymakers had access to relatively little empirical information regarding negotiation and mediation. Going forward, they are well-advised to keep abreast of current insights into the operation and dynamics of these processes. At the same time, it is important for increasingly well-constructed empirical studies to keep pace with the breadth and depth of our growing global experience.

\section{Growth of Professional Ranks, Regulation and Credentialing 220}

In the United States, mediation is an essential element in the equipage of 21 st century lawyers. As consumers of legal services put pressure on law firms to improve services and shorten dispute resolution cycle times while reducing cost, ${ }^{221}$ law schools (which are themselves increasingly driven by market pressures) are placing more emphasis on skills instruction, including clinics,

217 See David Maxwell "Gender Differences in Mediation Style and Their Impact on Mediator Effectiveness" (1991) 9 Mediation Quarterly 353 at 359 and 362, finding that female mediators achieved higher rates of settlement as an initial outcome of mediation ( 86.6 per cent versus 80.9 per cent) and had fewer broken settlements (7.4 per cent versus 16.4 per cent) than their male counterparts, while also admitting that the connection between meditation style and gender is only hypothetical.

218 See Phyllis E Bernard "Minorities, Mediation and Method: The View from One Court-Connected Mediation Program" (2008) 35 Fordham Urb LJ 1 at 1, 16-17 and 26-35.

219 See IAM/Straus Institute Survey, above n 21.

220 This section is based in part on Stipanowich, above n 1, at 374-377.

221 See J Stephen Poor "Re-Engineering the Business of Law" New York Times (New York, 7 May 2012) (oped by chairman of Seyfarth Shaw). 
externships and role-playing simulations. ${ }^{222}$ Prominent among these offerings are courses aimed at counselling and advocacy in negotiation, mediation and arbitration. 223

In addition, growing numbers are trying to derive a professional livelihood from the rendition of mediation services. Nearly half (47.7 per cent) of those responding to the 2014 IAM/Straus Institute Survey of experienced mediators indicated that mediation practice occupied 90 per cent or more of their work time. Almost 80 per cent (79.1 per cent) of the respondents devote more than half their time to mediation practice. Nearly three-quarters ( 73.8 per cent) of respondents had mediated 1,000 or more cases, ${ }^{224}$ and most believe they currently have a sufficient mediation caseload. ${ }^{225}$ This, however, is a cross-section of many of the world's leading commercial mediators, and cannot be taken as representative of the general run of individuals holding themselves out as mediators. Indeed, there are indications of a "professional crunch" in the ranks of would-be dispute resolution professionals. $^{226}$ As the first generations of ADR-acclimated attorneys - veterans of the Quiet Revolution - are moving from active practice into what many intend to be active retirement; many in their 60s, 70s and 80s are seeking employment as mediators and arbitrators alongside younger colleagues, many of whom are still in law practice..$^{227}$

Internationally, heightened interest in mediation has inspired many public and private programmes for the provision of related services.

Whether there is commensurate demand is another matter. Indeed, some countries have established a national framework for mediation but have yet to generate significant demand due to lack of understanding of the nature and value of mediation, and resistance by the legal profession. Take the example of Greece, which now has laws promoting and regulating mediation, including extensive guidelines for mediator training and accreditation, pursuant to which 1,000 mediators have

222 Catherine L Carpenter (ed) A Survey of Law School Curricula: 2002-2010 (American Bar Association: Section of Legal Education and Admissions to the Bar) at 15.

223 Julie Macfarlane "What Does the Changing Culture of Legal Practice Mean for Legal Education?" (2001) 20 Windsor YB Access Just 191. Pepperdine's Straus Institute is among programmes offering LLM and other master's degrees as well as a concentration in dispute resolution for law students.

224 See IAM/Straus Institute Survey, above n 21.

225 See IAM/Straus Institute Survey, above n 21.

226 Almost 60 per cent of respondents to our recent survey of experienced United States arbitrators indicated that they did not view their arbitration caseload as "sufficient": see Stipanowich and Ulrich, above n 171, at 415-417.

227 See Stipanowich, above n 1, at 374-376; and Kiser, above n 12, at 217. 
been credentialed. Greece lacks only one thing: parties and attorneys willing to mediate litigated cases! $!^{228}$

The apparent oversupply of individuals seeking employment as dispute resolution professionals, coupled with concerns about quality control, informed choice and transparency have driven growing international dialogue regarding professional credentialing. ${ }^{229}$ While there is no universally recognised international certification programme for mediators, there are a variety of private and public organisations that offer certification. Among the most visible entities is the International Mediation Institute, a private organisation that offers mediation professionals certification as "a key element of the wider IMI mission to promote quality assurance and professionalism in mediation". ${ }^{230}$ In the public realm, a number of United States states and state bar associations have considered creating credentialing criteria for mediators, ${ }^{231}$ and some countries have established national standards. ${ }^{232}$ Despite these initiatives, there are those who tend to view professionalisation and specialisation as developments that have undermined the early promise of mediation. ${ }^{233}$ Many questions remain about how credentialing should be done and who should do it.

228 Interview with lawyer-mediators Dimitra P Gavril and Theodora Syriou (8 August 2014) (notes on file with author).

229 See for example Doug Jones "Comments on the Speech of the Singapore Attorney General in International Arbitration: The Coming of a New Age?" in Albert Jan van den Berg (ed) International Arbitration: The Coming of a New Age? (Kluwer Law International, Alphen aan den Rijn, 2013) 29 (discussing certification of arbitrators and mediators through the Chartered Institute of Arbitrators (CIArb)); Irena Vanenkova "The Unique Value of Becoming IMI Certified" (February 2009) Mediate.com: Mediators \& Everything Mediation <www.mediate.com> (touting the IMI's worldwide credentialing system for mediators); Conrad C Daly "Accreditation: Mediation's Path to Professionalism" (2010) 4 Am J Mediation 39 (supporting accreditation of ADR professionals); and Deborah Sword "Professionalization of Conflict Resolvers" (July 2009) Mediate.com: Mediators \& Everything Mediation <www.mediate.com> (opposing certification efforts).

230 "IMI Certification in a Nutshell" International Mediation Institute <www.imimediation.org>.

231 See for example Michelle Vanisko "Mediator Certification: Should It Be Required in Montana?" (2014) 5 Mont LR 335 (discussing other states' certification programmes and evaluating the positives and negatives of implementing mediator certification programmes). See also Northern Virginia Mediation Service Stateby-State Guide to Court Mediator Qualification Standards (August 2013).

232 See generally Dendorfer-Ditges, above $\mathrm{n} 44$.

233 See for example Robert Benjamin "Killing Mediation: The Specialized, Professionalized and Neutralized Mediator" (February 2010) Mediate.com: Mediators \& Everything Mediation <www.mediate.com>. 


\section{BEYOND "GETTING TO YES": TOWARD A BROADER \\ CONCEPT OF FACILITATED RELATIONAL COMMUNICATION AND COLLABORATION}

[Mediation has the] capacity to reorient parties toward each other not by imposing rules on them, but by helping them to achieve a new and shared perception of their relationship, a perception that will redirect their attitudes and dispositions to each other. ${ }^{234}$

As mediation is promoted globally, we must continue to examine not only all of the different things that are being done, but also what has been left undone. In the latter respect, one largely untrodden path for the skills and insights of mediators is upstream - that is, at the point in relationships when conflict is budding into a full-fledged dispute, but before advocates are summoned, positions have hardened and, perhaps, the best opportunities for a problem solving approach to conflict are lost.

\section{A Moving "Upstream": Using Mediator Skills and Insights to Proactively Facilitate Long-Term Relationships}

Some years ago, my co-author Dwight Golann conducted a survey of mediators who had mediated different kinds of cases involving continuing relationships. ${ }^{235}$ His intent was to learn more about the situations where mediation plays a part in restoring a relationship or even brings about emotional reconciliation. He found that only about 17 per cent of relationships were restored, although in another 30 per cent of cases a resulting settlement incorporated so-called "integrative" terms - terms that were more valuable to a party than a purely monetary solution. ${ }^{236}$ The mediators Golann surveyed mentioned that, when it comes to restoring relationships, four factors are most important. The most frequently cited factor affecting the repair of a relationship was the stage of the dispute at which mediation occurred. ${ }^{237}$ The filing of a complaint or demand with a court or agency often greatly diminishes the prospects for a restoration. Over time, moreover, parties' positions and adversary postures harden. As time passes they may also be more likely to find other partners. ${ }^{238}$

Another factor was the relative value of the relationship to the parties, including the uniqueness of the relationship and sunk costs. ${ }^{239}$ Considerations included the perceived value of any alternatives, taking into account transaction costs (including reputational costs).

234 Lon L Fuller "Mediation: Its Form and Functions" (1971) 44 S Cal L Rev 305 at 325.

235 Dwight Golann "Legal Mediation: A Process of Repair - or Separation? An Empirical Study, and Its Implications" (2002) 7 Harv Negot L Rev 301.

236 At 311 , table 1 .

237 At $325-326$.

238 At $327-328$.

239 At $318-325$. 
A third key factor identified by the mediators was the attitudes of parties and counsel. Did the parties have the ability to understand their adversary's perspective on the dispute? Could they comprehend why their adversary believed they were in the right or why their acts might be excused? Could they recall the good feelings and values that animated the original relationship? An affirmative answer to these questions boded well as a first step to restoration of the relationship. ${ }^{240}$

The attitudes of counsel were mentioned even more frequently as a determinant of the efficacy of mediation in rebuilding relationships. ${ }^{241}$ Lawyers might hinder efforts at restoring relationships by a "narrow, adversarial attitude toward problems, ... [focus]ing only on legal issues or on distributive bargaining [rather than] ... broad-ranging discussions". ${ }^{242}$ Some lawyers "focus[ed] only on monetary issues, discourage[d] their clients from talking, and refuse[d] to explore relationship-based solutions". ${ }^{243}$ Other lawyers, however, understood the value of repairing relationships and were able to assist the mediator in that regard, or "take a back seat". 244

Finally, some of the mediators indicated it made a big difference if they had the opportunity to meet with the participants prior to the start of the formal mediation process. ${ }^{245}$ This was regarded as important, first, to permit the mediator to establish a personal relationship with the parties in dispute and, secondly, to explore imaginative solutions to current disputes that might require discussion of non-legal information and the involvement of people (such as accountants or family members) who would not normally be present in a formal mediation.

These factors affecting the likelihood of restoring relationships raise tantalising questions. What if we turned this situation on its head and, instead of focusing on repair of relationships in the context of dispute resolution, after parties have lawyered up and perhaps taken legal action, we focused on using the skills and insights of mediators to facilitate communication, understanding and collaboration in long-term relationships? Surely there are relational scenarios in which employing a proactive, deliberate approach using the skills of a third party can shore up the relationship and create a framework for anticipating and effectively managing conflict. With this in mind, let us reflect on the implications of each of Professor Golann's four factors.

240 At $328-329$.

241 At $329-331$.

242 At 329 .

243 At 330

244 At 330 .

245 At 331 


\section{Timing of intervention}

According to Professor Golann, the most frequently voiced factor for repairing relationships is the timing of a mediator's intervention in a dispute. Postponing this activity until after a relationship has been disrupted or undermined by a dispute, when positions harden, lawyers are selected, and, perhaps, complaints filed and "cover" - a substitute for the original relationship - has been sought out, substantially reduces the likelihood that a facilitator may be able to restore the relational status quo. Taking this reasoning one step further, might it not be even more advantageous to move facilitated intervention "upstream", to a point in the early stages of conflict and before the blossoming of a full-blown dispute? What if, indeed, facilitating could be directed, from the earliest stages of a relationship, to shoring up the bonds of understanding, trust, respect and solidarity that are the bedrock of partnership, and to promote effective collaboration among partners?

\section{Valued relationships}

A second key factor in the restoration of relationships through mediation is, of course, the value of a relationship to the parties relative to other choices. Not all relationships will survive the escalation of conflict into a legal dispute, and not all should. However, many relationships, whether between or within organisations, are sufficiently important to the parties that they are worth preserving and maintaining, either because of the prospective benefits to be obtained, the absence of satisfactory alternatives (including the costs of obtaining them) and the overall level of commitment to the existing relationship (including "sunk costs"). In some cases, the stakes associated with maintaining the relationship will be sufficiently important that it is worth investing in early facilitated relationship building, both in terms of the cost of retaining a skilled third party facilitator and ensuring the participation of key principals. As discussed below, many companies have been moved by concerns regarding the management of relationships in the workplace to invest in systems for proactive real-time management of workplace conflict. ${ }^{246} \mathrm{Such}$ investments might make sense in the context of important commercial relationships, or even international trade partnerships and international diplomacy. Another potential application is family-owned businesses, which form the backbone of the economy in many parts of the world.

\section{Attitudes of key participants.}

Mediators attempting to repair relationships also make much of the attitudes of parties and counsel. Importantly, unlike "legal mediation", proactive, pre-dispute facilitation of communication, understanding and collaboration need not cope with and seek to overcome the hardened, adversarial attitudes borne of active disputes. Perhaps more importantly, such intervention would not be complicated by the different agendas and attitudes of outside counsel, which are often unduly

246 Thomas Stipanowich "Real Time' Strategies for Relational Conflict" (2007) 3 International Bar Association 6 at 7 . 
adversarial and focused on narrow legal and factual questions, thereby preventing relationshiporiented discussions and solutions.

\section{Relationship of third party to principals, and scope of facilitation}

A final factor mentioned often by mediators focused on restoration of relationships is the importance of establishing a connection with the parties and exploring the opportunity for relational solutions (as opposed to purely distributive monetary settlements). Proactive, pre-dispute facilitation focused on the relationship would present an ideal platform for development of a strong and ongoing connection between the third-party facilitator with the parties and the relationship, and constant attention to the interests and priorities of the relationship and the individual parties. This involves embracing mediation as something more than a facilitated negotiation: a transformative or social process. ${ }^{247}$

Given the arguable appeal of the foregoing, one wonders why it has not been more broadly embraced by, for instance, businesses. Recognising the critical importance of addressing issues, conflict and disputes in the workplace, many companies have established multi-faceted systems, including support mechanisms and intervention strategies aimed at real-time management of employment relations. ${ }^{248}$ These experiences have not, however, significantly "cross-pollinated" approaches to managing conflict in the broad realm of commercial relationships, or even relations between different departmental or corporate cultures within companies. One might conclude that proactive, deliberate facilitation of communication, understanding and collaboration in commercial relationships has not caught on because, to employ a Hobbesian perspective, companies simply perceive no utility or fit in such approaches. This may be so, but it is a fact that such approaches do exist in the real world and not simply in the realm of imagination.

\section{B Object Lessons: Partnering, Dispute Resolution Advisers and Project Neutrals}

By the last decade of the 20th century the United States construction industry was sick, concluded the Construction Industry Institute (CII); the malady was the growth of litigation. The Business Roundtable found the construction industry to be one of America's least efficient sectors, largely because of the "'adversarial dance' between parties to the construction project, ... [creating] 'a constant state of confrontation'". ${ }^{249}$ In earlier times, construction claims and controversies were usually resolved informally and early through jobsite negotiation, decisions by design professionals,

247 Joseph P Folger and Robert A Baruch Bush "Transformative Mediation and Third-Party Intervention: Ten Hallmarks of a Transformative Approach to Practice" (1996) 13 Mediation Quarterly 263 at 263-278.

248 Stipanowich, above n 246 , at 7.

249 Thomas Stipanowich "Managing Construction Conflict: Unfinished Revolution, Continuing Evolution" (2014) 34 The Construction Lawyer (Journal of the ABA Forum on Construction Law) 13 at 14. 
or, if necessary, informal binding arbitration without much lawyer involvement. But things had changed due to the growing size and complexity of the industry, inflationary pressures on contractors, tighter owner budgets and time frames for construction, and risk-shifting by owners. More emphasis was placed on lawyered adversarial processes, with many disputes being postponed and eventually consolidated in massive arbitration or litigation proceedings. The economic, business and relational costs were huge. ${ }^{250}$

Suddenly it seemed everyone was exploring and proposing solutions to the construction industry's crisis. ${ }^{251}$ These included initiatives focused on tackling the roots of construction conflict and promoting jobsite collaboration, including "partnering" at the project level. A concept borrowed from the manufacturing and distribution sectors and pioneered by the United States Army Corps of Engineers, partnering was designed to encourage collaboration and team work by deliberate early efforts to create an atmosphere of trust and cooperation on projects. ${ }^{252}$ Facilitated partnering workshops were commonly conducted shortly after contract signing and attended by owner representatives and key members of the design and construction team. The aim was stronger individual bonds, better understanding of each other's objectives and expectations, and nonadversarial approaches for resolving problems on the job. ${ }^{253}$ In the mid-1990s, surveyed contractors saw partnering as a superior means of reducing dispute-related time and cost, enhancing understanding, opening channels of communication and preserving job relationships. ${ }^{254}$ The large majority of contractors expected its usage to grow. ${ }^{255}$

As a partnering facilitator on private contracts, I saw the potentially positive effect of proactive relational facilitation, and had the opportunity to apply it not just on construction projects, but in another kind of commercial joint venture. One of the transactional attorneys who participated in the partnering conference told me that he found the experience uniquely beneficial in allowing him to better understand the goals and needs of his own client and partners, and to conceptually "put flesh on the bones" of the agreement he had helped negotiate.

250 At 14 .

251 At 14 .

252 At 14; and see also Adam K Bult and others Navigant Construction Forum, Delivering Dispute Free Construction Projects: Part III - Alternative Dispute Resolution (Navigant Construction Forum, June 2014) at $7-10$.

253 Bult and others, above $\mathrm{n} 252$, at 7-10.

254 Stipanowich, above n 71, at 147, table DD-4.

255 Stipanowich, above n 71, at 156, 156, table EE-4. See also Erik Larson "Project Partnering: Results of Study of 280 Construction Projects" (1992) 11(2) J of Management in Eng'g 30. 
The impetus that inspired project partnering also gave rise to dynamic, proactive relational conflict management in the form of the Dispute Resolution Advisor (DRA). ${ }^{256}$ In 1991, a customdesigned system for the renovation of a Hong Kong hospital incorporated many different elements in a programme that represented a quantum leap in the evolution of jobsite dispute resolution and "project neutrals". Because the contract called for demolition and construction to be performed while keeping the hospital and operating theatres operational, the public owner required a system that would identify and resolve disputes in the shortest possible time and prior to completion of the project. The result was a programme with tight time frames for jobsite decision making and handling of claims, and a flexible, dynamic dispute resolution system centred upon the figure of a DRA, a construction expert with dispute resolution skills who would remain throughout the project. The DRA first met with job participants to explain and build support for a cooperative approach to problem solving. Thereafter, the DRA made monthly visits to the site to monitor the status of the job and facilitate discussions regarding emerging issues. In the event of a formal challenge to a project decision, certificate or evaluation, the parties were given time to resolve the matter through negotiation, failing which the DRA could make arrangements for mediation, mini-trial or expert fact-finding. If assisted site level negotiations failed, the DRA was to prepare a report identifying the key issues in dispute, the positions of the parties and perceived barriers to settlement, and make either a recommendation for settlement or a nonbinding evaluation of the dispute. The report would be used by senior off-site representatives of the parties in further negotiations, perhaps assisted by the DRA. Should matters not be resolved within 14 days of the issuance of the DRA's report, the DRA would set into motion a short-form arbitration procedure or other mutually acceptable means recommended by the DRA. The DRA procedure worked well. Despite the usual problems and several hundred owner-ordered changes, no disputes reached the stage of nonbinding evaluation. ${ }^{257}$

Despite the early expectations of many in the industry, partnering never came into general usage; it does, however, remain a feature of public construction programmes, notably state departments of transportation. Some studies have indicated that the use of partnering has resulted in more projects being completed on or ahead of schedule, in improved contract administration, reduced claims and disputes, reduced owner engineering and administrative expenses, and more value engineering. ${ }^{258}$ The California Department of Transportation employs project partnering

256 Colin J Wall "The dispute resolution adviser in the construction industry" in Peter Fenn and Rod Gameson (eds) Construction Conflict Management and Resolution (E \& FN Spon, London, 1992) 328.

257 Thomas Stipanowich "The Multi-Door Contract and Other Possibilities" (1998) 13 Ohio State J on Disp Resol 303 at 387-389.

258 Bult and others, above n 252, at 9. 
alongside project-based dispute review boards (DRBs) (for projects over $\$ 10$ million) ${ }^{259}$ and DRAs. ${ }^{260}$

DRAs have seen limited use, although the highly customised and dynamic approach used in Hong Kong may not have been replicated in other venues. However, the appointment of a "standing" dispute resolution professional to mediate issues as they arise during the course of a construction project has proven valuable in keeping the job on track and helping to limit the number of claims that must be subjected to more formal and expensive dispute resolution procedures. ${ }^{261} \mathrm{As}$ a project neutral on a public works project, I facilitated discussions at job meetings among key construction team members, encouraging clearer communication and action steps to address emerging problems at the outset, thereby avoiding the development of legal disputes. However, in contrast to "mainstream mediation" - that is, post-dispute "legal mediation" involving lawyerdominated mediation of cases on the road to litigation - the "standing mediator" format has been embraced relatively rarely.

Although it is not entirely clear why they have never achieved the broad usage anticipated by their early proponents, relationship-oriented facilitation approaches such as partnering, DRAs and standing or project neutrals represent examples of what might be possible, not just in the realm of construction contracting but also in other relational scenarios. ${ }^{262}$ Of course, there are substantial barriers to the adoption of such radically different paradigms.

259 Stipanowich, above n 249, at 16 .

260 Zack, above n 90, at 4-5.

261 See Gould, King and Britton, above n 165, at 17, discussing project mediation in the United Kingdom and CEDR's Project Mediation package.

262 A project initiated by the author as President and CEO of the International Institute for Conflict Prevention and Resolution (CPR Institute) through the CPR Committee on Information Technology Conflict Management sought to apply concepts of project partnering to ventures between IT providers and companies. The single pilot project undertaken in connection with this initiative suggested a number of ways in which partnering might "lay a strong foundation" for relational contracting, including:

(1) clarifying organisational structure;

(2) strengthening internal communications;

(3) strengthening communications between co-venturing partners;

(4) clarifying vision and goals; testing assumptions;

(5) incorporating strategic business goals;

(6) focusing on reasons for past failures and successes;

(7) establishing a process to accommodate change;

(8) establishing an issue resolution process / resolution ladder; and

(9) facilitating team building.

CPR Committee on Information Technology Conflict Management Avoiding and Resolving Information Technology Disputes: Better Solutions for Business (2005) at 19-23. 


\section{Barriers - and Overcoming Them}

Just as the use of mediation was met with resistance from those who do not perceive that it adds value in the resolution of disputes, third-party facilitation for the purpose of building and maintaining a collaborative relationship will not be embraced by organisations that fail to see benefits in excess of its costs. Despite the fact that analogues may exist in the form of ombudsmen in the workplace or marriage counsellors, there are sizeable obstacles in the way of promoting such approaches in commercial relationships.

Business people are likely to be sceptical of the whole concept of devoting time and resources to an effort above and beyond the normal process of deal-making and day-to-day contract performance. They may wonder why, if business people are adept at business relationships and lawyers are there to handle the conflict, there is a need for anything or anyone else. Having someone facilitate improved communications, understanding of one another's perspectives and priorities, and promoting collaboration may conjure up images of a counsellor's couch, sensitivity training or a homeopathic remedy. In-house attorneys are likely to have even less resonance with such concepts. And outside counsel, full of advice (good or bad) on dispute resolution methods, are likely to be entirely clueless when it comes to upstream activities of this kind.

It is critical to communicate a clear and persuasive value proposition for relational facilitation aimed at strengthening relationships and avoiding destructive conflict, just as preventive medicine (including the promotion of exercise and proper nutrition) is put forward as a way of avoiding the cost and risk of traditional medical treatment. The new paradigm would need to be explained in terms of business goals, including:

(1) establishing closer individual and organisational relationships, and improving communications with business partners and even within organisations;

(2) coming to a better understand of each other's goals, priorities and ways of dealing with problems that emerge in the relationship(s);

(3) managing issues and conflict in the relationship in a constructive way, exploring outcomes that address business objectives and preserve relationships;

(4) where disputes arise, handling them in such a way as to prevent them from escalating into a costly, protracted and burdensome drain on company resources, and to achieve faster, cheaper and more satisfying results, ${ }^{263}$ and

263 Some of the concepts here presented are inspired by and based in part upon discussions by the author, Peter Benner, Debra Gerardi, Emily Gould, Jeremy Lack and Bill Logue, who along with Professor Ann Feyerherm, Karel Kreshek and Nancy Vanderlip planned "Re-Imagining Corporate Conflict Management", a workshop held at Pepperdine University on 17 and 18 September 2014 and co-sponsored by the Straus Institute for Dispute Resolution and the Graduate School of Business Management. 
(5) considering the dispute resolution process itself (and its likely consequences on the parties' behaviour) as part of the problem to be addressed.

Perhaps the only way to convince businesses and other organisations of the utility of such approaches is through first-hand experience or reliable accounts of other's success stories. ${ }^{264}$ Many United States business users and counsel became acquainted with mediation as a result of the encouragement - or mandate - of courts of law, and later, administrative agencies; today, mediation is integrated into many stepped contractual dispute resolution programmes. Proactive conflict management approaches may also be seen as elements of organisational risk management strategy, corporate social responsibility or even brand management. Similarly, opportunities must be found to beta-test partnering approaches or other relational facilitation programmes, ${ }^{265}$ thereby hopefully laying the groundwork for their eventually successful implementation and, ultimately, broader adoption as a matter of corporate culture and identity. ${ }^{266}$

\section{The Broad Potential Scope for Facilitation in Key Relationships}

What kinds of relationships might be most fitted to the introduction of a form of partnering, or relational facilitation? The most obvious candidates are long-term contracts involving major commitments of resources, or high stakes for the partners or business community. Facilitation may be particularly valuable in relational scenarios involving multiple parties and complicated, one-of-akind products, such as construction projects or the development of customised software or IT systems.

Ongoing relational facilitation could also be of special value in the context of inter-cultural relationships, whether the "cultures" are associated with ethnicity, nationality or professional discipline. This may be particularly true in the case where the parties have very different notions of the concept of a contractual relationship and the meaning of a written integration of the contract. For a United States business person, it is all about "Getting to Yes" in the sense of a deal, which usually means negotiated terms memorialised in writing; the latter is the endpoint of negotiation and the touchstone or measuring stick for the subsequent relationship. But for a counterpart from, say, certain Asian cultures, the initial "Yes" may be but a starting point for the relationship - perhaps

264 United States Army Corps of Engineers developed and published case studies.

265 See n 262, above.

266 Wolf von Kumberg suggests: "If early issue resolution is to take place, management rather than lawyers must be empowered to deal with conflict resolution. ... Inserting project mediators into programme management would permit issues to be resolved in most cases by project management without the need for lawyers in most cases. To bring about this process change within companies, because that is what is needed, business management must be educated and trained to deal with conflict management." Email from Wolf von Kumberg (IMI Board Member and former European Legal Director and Assistance General Counsel, Northrup Grumman Corporation) to author (7 September 2015). 
only a snapshot of where the parties are at a point in time. ${ }^{267}$ Down the road, beyond that initial "Yes", the parties' mutual future is dynamic; there may be many possibilities and exigencies that require adjustment and recalibration of the terms of the relationship. ${ }^{268}$ In this kind of scenario, might the need for a facilitator extend "beyond 'Getting to Yes"' through the life of the relationship? If so, it might prove beneficial not only in commercial relationships but also in relations between states as major trading partners.

\section{E The Equipage of a Relational Facilitator}

What skills and experience might be desirable in a facilitator retained for the purpose of helping parties make the most of their relationship and minimising the effect of destructive conflict by promoting communication, mutual understanding and collaboration? Several elements suggest themselves:

(1) the ability to establish personal rapport and mutual trust with the parties, and to inspire and maintain the same kinds of bonds between and among the participants;

(2) experience as a mediator with an understanding and skills in facilitating interest-based bargaining as well as distributive bargaining, and the ability to bring to bear appropriate skills at the proper time;

(3) a strong working familiarity with the commercial setting of the relationship, including the normal range of business expectations, including usages of trade, as well as potential longterm relational dynamics, changed circumstances and common "cases of trouble";

(4) a thorough appreciation of the impact of and interaction between personalities of different types in ongoing relationships, as well as the many kinds of "cognitive filtering" that may occur in the course of a relationship;

(5) a penetrating awareness and appreciation of the various cultures at play, including their respective negotiating "codes"; and

267 John Barkai "What's a Cross-Cultural Mediator to Do? A Low-Context Solution for a High-Context Problem" (2008) 10 Cardozo J Conflict Resol 43 at 54.

268 At 53-54, Barkai emphasises the varying importance of relationships in the context of cross-cultural mediation: "Although Asian business people might see the importance of establishing (or re-establishing) a good working relationship between the negotiators at the mediation, some Americans might be reluctant to spend time in such a pre-mediation stage. However, the cross-cultural mediator can call upon the mediator's power to bring the parties together in a caucus with the intent to re-establish the pre-dispute relationship, or at least to improve the relationship. My friend and sometime co-teacher, David Day, describes cross-cultural mediation as 'put[ting] Humpty Dumpty back together,' suggesting that a fragile, egg-like relationship has been cracked and needs to be somehow repaired. Of course, it is very difficult to put fragile Humpty Dumpty back together again, unless there is an understanding of how the Humpty Dumpty business deal was put together in the first place." 
(6) a working familiarity with a spectrum of options for managing conflict at different stages, including for example, early expert evaluation, fact-finding, mediation, conciliation, medarb and arbitration.

It remains to be seen whether the concept of employing the skills and insights of mediators to ongoing relational facilitation catches on. It might be that many of the same benefits could be obtained through the use of other formats such as the use of conflict coaches and consultants. Time will tell.

\section{CONCLUSION}

The reverberations of the Quiet Revolution that began in the 1970s have been felt in countries around the globe. They have given rise to a proliferating array of institutions, programmes, directives and laws, and an international movement with evangelical aims, including the promulgation of an international convention that might supercharge the enforcement and recognition of mediated settlement agreements.

At such a time as this, it is appropriate to reflect and deliberate on where we have come to and where we are going. Our evolving experience raises a host of questions and concerns, including:

- $\quad$ our fundamental understanding of the nature of mediation, its aims, and the techniques and approaches that are most effective and appropriate in achieving its goals;

- the significant impact of legal advisors on mediation, and the appropriate interplay between lawyer and client;

- $\quad$ the pervasive influence of culture and of legal traditions;

- $\quad$ the interplay between the facilitation of settlement and adjudicative process;

- the potential impact of mediation on the rendition of justice;

- the challenges and opportunities presented by current trends, including the technological revolution, research involving brain science and "big data", and efforts to promote professionalism; and

- $\quad$ unfulfilled opportunities, such as the "upstream" use of the skills and insights gleaned from our experience with mediation for the purpose of sustaining and improving relationships.

The time is ripe for a broad-based, well-organised and ongoing initiative aimed at more systematically obtaining reliable information about our varied experiences with mediation and its place in the broader landscape of conflict management, as well as facilitating greater mutual understanding of how and why we do what we do. The hoped-for result would be more reflective conduct by dispute resolution professionals and legal practitioners as well as better-informed public policy and standard-setting. 
